\title{
Depth-sensing indentation tests in studying plastic instabilities
}

\author{
N.Q. Chinh, J. Gubicza, Zs. Kovács, and J. Lendvai \\ Department of General Physics, Eötvös University, Budapest, 1117 Budapest, Hungary
}

(Received 13 June 2003; accepted 29 September 2003)

This review surveys the phenomenon of plastic instabilities occurring in depth-sensing indentation measurements. Investigations presented focus on the characterization of Portevin-Le Châtelier type instabilities observed in different metal alloys during indentation. The effect of some important factors such as solute concentration, the formation of Guinier-Preston zones, and grain size and orientation are described and discussed. The phenomenon of plastic instabilities as serrated flow recently observed in bulk metallic glasses is also briefly reviewed.

\section{GENERAL APPLICATIONS OF DEPTH-SENSING INDENTATION METHOD}

In the last two decades, depth-sensing indentation (DSI) became widely used for the mechanical characterization of solids. The reason for its popularity is that DSI enables the determination of mechanical properties even for a small volume of material without complicated sample preparation. The DSI method is an improvement over conventional hardness measurement. The most important motivations of this development are the following: (i) the optical evaluation of extremely small indentations in hard materials and thin layers is very uncertain, (ii) the DSI enables the measurement of the depth profile of the hardness perpendicular to the surface in gradient materials, (iii) the method allows the study of changes in the hardness during deformation under load (dynamic hardness), and (iv) the penetration or the loading rate, which affect the hardness value, can be selected and controlled during indentation.

During the DSI process, an indenter is penetrated into the surface of the material with constant indentation rate or loading rate. In the majority of the measurements, the loading rate is held constant. When the load reaches its selected maximum value, the load decreases with the same rate as for loading and the indenter moves backward. The load-penetration depth curves are recorded in both the loading and the unloading parts of the measurement as schematically shown in Fig. 1. The characteristic features of these curves are used for the determination of mechanical properties of solids. The shape of the loading and unloading curves depend on the geometry of the indenter, the loading rate, the testing temperature, and, of course, the mechanical properties of the material.

For the most often used Vickers and Berkovich type indenters, the relationship between the load $(F)$ and the penetration depth $(h)$ for the loading curve is usually approximated by a quadratic function:

$$
F=C h^{2},
$$

where $C$ is a constant depending on the geometry of the indenter and the elastic and plastic properties of the material. This relation has been recovered by numerical simulation for both elastic-perfect plastic and elasticplastic materials ${ }^{1-3}$ and confirmed also by experimental results. ${ }^{4-7}$ Assuming perfect tip shape and that the indentation holds the shape of the indenter, the hardness number $(H)$, defined as the ratio of the load and the contact area, can be expressed as

$$
H=0.038 \frac{F}{h^{2}} \text { (for Vickers indenter) . }
$$

If Eq. (1) is valid, $H$ can be regarded as a loadindependent hardness number (often called universal hardness). Many experimental results (e.g., Refs. 2, 8) have shown that $H$ deviates from the conventional hardness determined by optical evaluation of the indentation pattern after unloading. This difference is a consequence of the pile-up and sinking-in of the material around the pattern. It has been found, further, that $H$ generally increases with decreasing the applied load. ${ }^{8-11}$ This phenomenon is called indentation size effect (ISE), the origin of which is not yet entirely clear. It has been proved, however, that the friction between the indenter and the material, ${ }^{9,12,13}$ the imperfections of the geometry of the indenter tip, ${ }^{10}$ and/or the occurrence of so-called geometrically necessary dislocations ${ }^{11}$ may cause similar effects. From the load-dependence of the hardness number $H$, one can conclude that Eq. (1) is not valid for the whole range of loads from nanoindentation $(F \approx 10$ to $100 \mu \mathrm{N})$ to macroindentation $(F \approx 10$ to $100 \mathrm{~N})$.

Experimental results have shown that in many cases the loading curve cannot be fitted satisfactorily by a pure quadratic formula. ${ }^{14-21}$ Instead of Eq. (1), two approximations of the loading curve have been elaborated: fitting by (i) power law or (ii) second-order polynomial. 


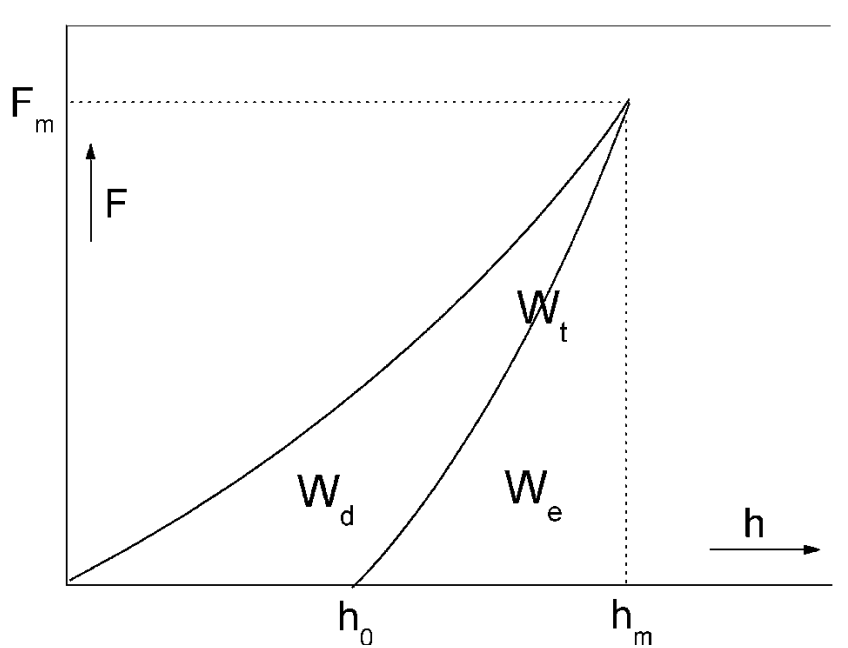

FIG. 1. Schematic of a load-depth $(F-h)$ indentation curve.

Both of them are capable of taking the ISE into account. In the first approximation, the loading curve is fitted by power-law function ${ }^{14-17}$

$$
F=\mathrm{Ch}^{\alpha}
$$

where the experimental value of $\alpha$ is less than 2 , indicating the existence of ISE. The value of $\alpha$ in general depends on the mechanical behavior of the material; for example, for alumina or aluminum alloys $\alpha=1.75$ to 1.90 has been found ${ }^{15,16}$ whereas for $\mathrm{Sn}-3.5 \mathrm{Ag}-0.75 \mathrm{Cu}$, $\alpha \approx 1.5$ has been found. ${ }^{17}$ In the latter case, the deformation showed significant creep behavior because the homologous temperature of this Sn-based alloy is 0.61 at room temperature (RT). It was shown that for materials where the creep deformation cannot be neglected during indentation, $\alpha=2 /(m+1)$, where $m$ is the strain rate sensitivity. ${ }^{17}$ The higher the $m$, the higher the deviation of $\alpha$ from 2. For creep deformation, the coefficient $C$ in Eq. (3) depends strongly on the loading rate.

In another approximation, the loading curve is fitted by second-order polynomial ${ }^{18-21}$

$$
F=c_{2} h+c_{3} h^{2},
$$

where $c_{2}$ and $c_{3}$ are constants depending on the mechanical properties of the material and the indenter geometry. Integrating Eq. (4) by $h$, the first and the second terms in the indentation work are proportional with $h^{2}$ and $h^{3}$, respectively. According to the explanation of Fröhlich and co-workers, ${ }^{18}$ the first term corresponds to the work expended to the increase of the surface under the tip and the formation and propagation of cracks whereas the second term is responsible for the elastic-plastic deformation. The mechanical properties are characterized by a load-independent hardness number defined as $H=$ $0.038 c_{3} \cdot{ }^{18}$ Krell and Schadlich ${ }^{15}$ have shown that if a "roof edge" existed at the tip of the indenter, an additional linear term was required in Eq. (1). According to their calculations, the $F-h$ relation for a Vickers pyramid can be expressed as

$$
F=26.43 H h^{2}+\frac{2 c H}{\cos 68^{\circ}} h,
$$

where $c$ is the length of the roof edge and $H$ is a loadindependent hardness number. Gubicza et al. ${ }^{19-21}$ have studied the load-penetration depth curves for a wide range of materials from metals to ceramics in the macrohardness region with the maximum applied load of about $100 \mathrm{~N}$. Both the loading and the unloading curves were fitted by second-order polynomials. The hardness was determined by the following empirical formula ${ }^{19,20}$

$$
H=0.038 c_{3} \frac{W_{\mathrm{t}}}{W_{\mathrm{d}}},
$$

where $W_{\mathrm{t}}$ is the total work performed during loading and $W_{\mathrm{d}}$ is the work dissipated during a loading-unloading cycle (Fig. 1). Using the work quantities, the elastic modulus was given in the form ${ }^{19,20}$

$$
E=0.71\left(1-v^{2}\right) c_{3}^{*} \frac{W_{\mathrm{e}}}{W_{\mathrm{t}}},
$$

where $v$ is the Poisson ratio of the material, $c_{3}^{*}$ is the coefficient of the second-order term in the polynomial fitted to the unloading curve, and $W_{\mathrm{e}}$ is the elastic work recovered during unloading. It was shown that the hardness and the elastic modulus calculated by Eqs. (6) and (7), respectively, agreed well with the values determined by conventional methods for different materials from metals and polymers to ceramics. ${ }^{19-21}$ It was also proved that these empirical equations satisfied the theoretical formulas calculated for the ideally elastic and rigidplastic materials.

Oliver and Pharr ${ }^{22,23}$ have developed a procedure that enables the determination of the hardness and the elastic modulus from the unloading part of the indentation curve. This method is the most often used procedure for the evaluation of the instrumented indentation in the literature. The hardness is determined as the ratio of the maximum load and the projected contact area. The latter can be expressed as a product of a geometrical constant and the square of the contact indentation depth $\left(h_{\mathrm{c}}\right)$. The contact depth can be obtained as

$$
h_{\mathrm{c}}=h_{\mathrm{m}}-\epsilon \frac{F_{\mathrm{m}}}{S},
$$

where $h_{\mathrm{m}}$ and $F_{\mathrm{m}}$ are the maximum penetration depth and load, respectively, $S=\mathrm{d} P / \mathrm{d} h$ is the slope of the unloading curve at $h_{\mathrm{m}}$, and $\epsilon=0.75$. The elastic modulus has been expressed in terms of $S$ and the projected contact area $(A)$ as 


$$
E=\left(1-v^{2}\right) \frac{S}{\beta \sqrt{A}}
$$

where $\beta=1.168$ and 1.142 for Berkovich and Vickers indenters, respectively. The initial slope of the unloading curve is generally calculated by derivating the power-law function fitted on the unloading data. Numerous experimental works (e.g., Refs. 10,14, 24-28) have proved that the hardness and the elastic modulus determined in this way agreed well with the data measured by other methods or found in databases. The errors associated with the determination of the hardness and elastic modulus by DSI have been discussed in detail by Mencik and Swain. ${ }^{10}$ These errors are generally attributed to the uncertainty in the determination of the origin of the loading curve, the imperfections of the indenter tip, the uncertain elastic stiffness of the measuring device, and the pile-up of the material around the indentation pattern.

By overviewing the literature of the instrumented indentation, the most often used application of the DSI technique is the determination of the hardness and the elastic modulus of materials. Because the penetration depth is recorded permanently during deformation, DSI enables monitoring of processes that result in changes in the penetration depth under load. Therefore, the method is suitable for the investigation of, for example, stressinduced phase transformations, ${ }^{29}$ creep deformation, ${ }^{30}$ surface cracking in coatings, ${ }^{31,32}$ and recently, plastic instabilities. ${ }^{16,33-42}$

The aim of this paper is to review the phenomenon and characterization of plastic instabilities during depthsensing indentation tests. In this review, unless otherwise stated, results obtained by using Vickers indenter at constant loading rate are reported, and the composition of materials is given in weight percent.

\section{PLASTIC INSTABILITIES IN METAL ALLOYS DURING INDENTATION TESTS}

\section{A. Introduction}

Plastic instabilities as the phenomenon of discontinuous yielding during plastic deformation have widely been observed and discussed in the literature under various names, such as serrated yielding, Portevin-Le Châtelier (PLC) effect, jerky flow, and so forth. ${ }^{43-47}$ In unidirectional deformation, the most characteristic feature is the appearance of stress drops or stress jumps, $\Delta \sigma$ beginning from a critical strain, $\epsilon_{\mathrm{c}}$, on the originally smooth stressstrain curves. Therefore, several works focused both theoretically ${ }^{48-51}$ and experimentally ${ }^{46,52,53}$ on the interpretation and determination of the parameter $\Delta \sigma$. The physical basis for the appearance of the PLC effect is a negative strain rate sensitivity (SRS) originating mainly from the interaction between mobile dislocations and diffusing solute atoms during plastic deformation, a phenomenon called dynamic strain ageing (DSA).$^{54-57}$ Depending on the testing conditions, negative SRS may occur at a certain part of the N-shaped stress-strain rate $(\sigma-\dot{\epsilon})$ function shown schematically in Fig. $2 .{ }^{47}$ Several models have been developed both on the solutedislocation interaction ${ }^{58-61}$ and on the explicit expression of the mentioned $\mathrm{N}$-shaped $\sigma-\dot{\epsilon}$ function. ${ }^{62,63}$

Although the PLC effect has been observed and investigated mainly by uniaxial tensile and compression tests, ${ }^{46,53,59}$ it was also studied in other modes of deformation. ${ }^{64}$ Recently, the phenomenon of PLC plastic instabilities in metals was investigated also by DSI. ${ }^{16,33-42}$ In the following, these results will briefly be summarized.

\section{B. The phenomenon of plastic instabilities in DSI tests}

During DSI, the load, $F$, is increased at constant loading rate, $v_{l}$, so that at a moment, $t$, the load $F(t)=v_{l} t$. Some typical depth-load curves obtained on different samples are shown in Fig. 3. Two types of the indentation depth-load curves can be distinguished: (i) for instance, on pure $\mathrm{Al}$, a smoothly changing curve appeared, and (ii) for several solid solution alloys-such as $\mathrm{Al}-\mathrm{Mg}$ and $\mathrm{Al}-\mathrm{Cu}$, which can usually be regarded as model materials showing plastic instabilities in tensile measurementsfrom a certain critical load, $F_{\mathrm{c}}$ (and a corresponding critical depth, $h_{\mathrm{c}}$ ), characteristic steps appear in the $h-F$ curves. It has been shown that the occurrence and the development of the steps depend both on the loading rate and on the composition of the alloy. ${ }^{16,33}$ Analyzing the depth-load curves containing steps, the indentation process can physically be regarded as a series of two subsequent local processes in which, first, the deformation (indentation depth) increases rapidly at practically no increase in load, and then the load increases by $\Delta F_{\mathrm{p}}$ at essentially negligible increase in the indentation depth.

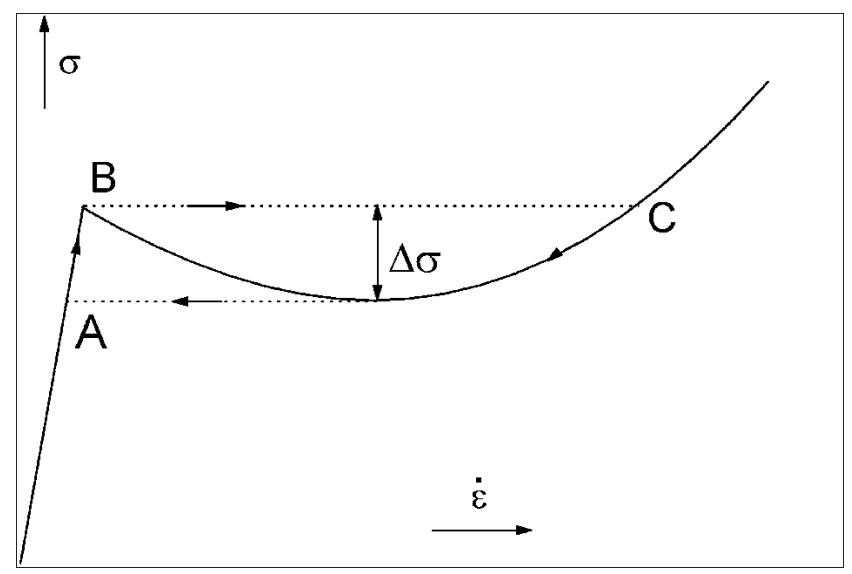

FIG. 2. Schematic of the N-shaped stress-strain rate $(\sigma-\dot{\epsilon})$ function of alloys showing PLC plastic instabilities. 


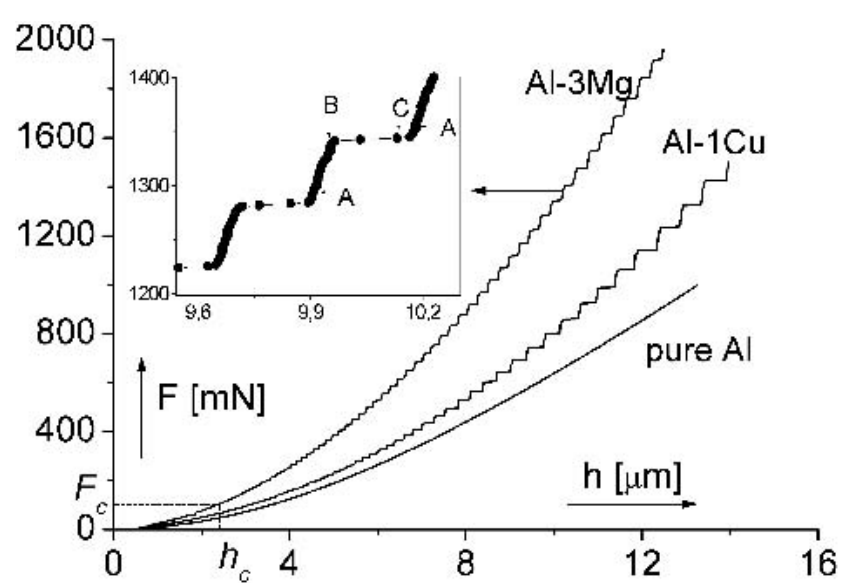

FIG. 3. Typical indentation depth-load curves obtained in the dynamic microhardness tests.

Figure 4 shows the Vickers microhardness, $H V$, calculated by Eq. (2) from the $h-F$ curves presented in Fig. 3 as a function of the indentation depth, $h$. In the case of pure $\mathrm{Al}, H V$ is a smooth function of the indentation depth. Considering the step-containing indentation curves, however, $H V$ oscillates quasi-periodically. This phenomenon corresponds to the serrated yielding (Portevin-Le Châtelier effect) observed in tensile tests. In both types of measurements, the phenomenon manifests itself in the occurrence of the successive low (denoted as $\mathrm{AB}$ in Figs. 2, 3, and 4) and high (denoted as $\mathrm{BC)}$ strain rate regimes and, of course, in the accompanied hardness and stress jumps, $\Delta H V$ and $\Delta \sigma$, respectively.

\section{Characterization of plastic instabilities occurring in depth-sensing indentation tests}

1. Development of instability steps in stable solid solutions

In an early paper on indentation instability, Bérces et al. $^{33}$ have given a kinematic analysis of the development of the instability steps observed on $\mathrm{Al}-3 \mathrm{Mg}$ alloy

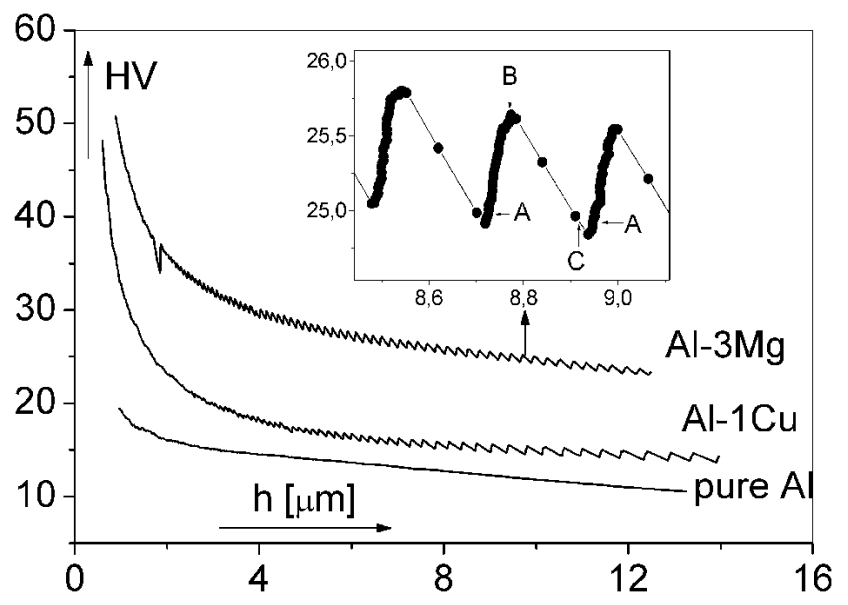

FIG. 4. $H V$ changes during indentation; obtained from $F-h$ curves shown in Fig. 3. with grain size larger than $500 \mu \mathrm{m}$. In Fig. 5, five indentation curves can be seen which were obtained at $v_{l}=14$ $\mathrm{mN} / \mathrm{s}$ loading rate in one selected grain of the specimen. The curves demonstrate the reproducibility of the experiments. The formation of instability steps on the originally smooth curves sets in at a well-defined $F_{\mathrm{c}}-h_{\mathrm{c}}$ point. A part of a curve is shown in Fig. 6 in higher resolution, in which the load period, $\Delta F_{\mathrm{p}}$, and the height of the stairs, $\Delta D_{\mathrm{p}}$, are defined at a given $F-h$ point on the curve. Analyzing the development of the steps, it has been shown that both

$$
\frac{\Delta D_{\mathrm{p}}}{h},
$$

and

$$
\frac{\Delta F_{\mathrm{p}}}{F}
$$

are approximately constant; that is, the step height, $\Delta D_{\mathrm{p}}$, and the load period, $\Delta F_{\mathrm{p}}$, characterizing instability steps are proportional to the total indentation depth and the total load, respectively.

Figure 7 shows indentation depth-load curves measured at different $v_{l}$ loading rates on the same $\mathrm{Al}-3 \mathrm{Mg}$ alloy. On the basis of this figure, it can be established that decreasing loading rate, $v_{l}$, makes (i) the stairs more rectangular, (ii) the "plateau" of the steps flatter, (iii) the load period of the step at a given load greater, and (iv) the critical load, $F_{\mathrm{c}}$, smaller.

The same features were also observed during serrated indentation of bulk metallic glasses (BMGs). ${ }^{65}$

Returning to the $\mathrm{Al}-3 \mathrm{Mg}$ alloy, investigating the value of critical load, $F_{\mathrm{c}}$ - the load belonging to the onset point of stair formation-it has been pointed out that $F_{\mathrm{c}}$ is proportional to the loading rate, $v_{l}^{33}$

$$
F_{\mathrm{c}}=t_{\mathrm{c}} \times v_{l},
$$

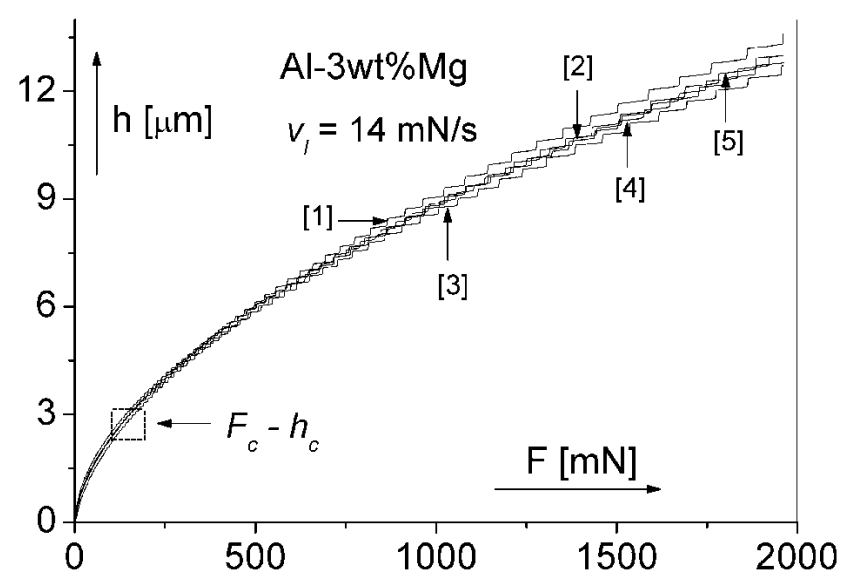

FIG. 5. Five indentation curves measured in the same grain of an Al-3Mg sample. ${ }^{33}$ 


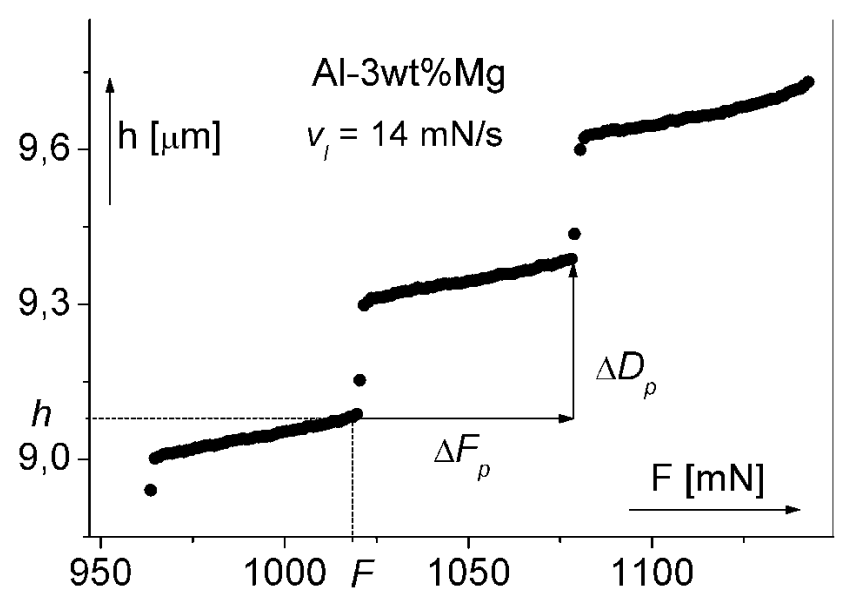

FIG. 6. Indentation depth-load curve in high magnification illustrating the definition of $\Delta F_{\mathrm{p}}$ and $\Delta D_{\mathrm{p}}$.

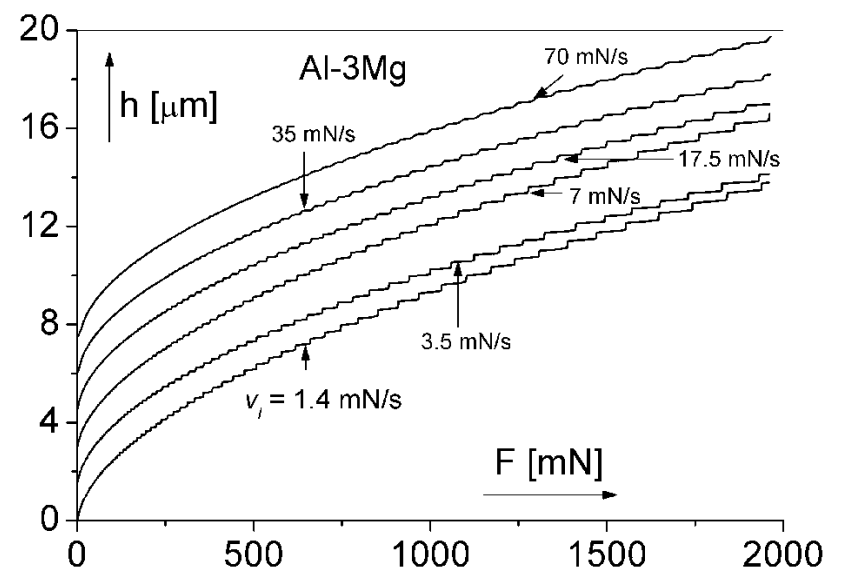

FIG. 7. Indentation curves measured at different loading rates (the curves are shifted vertically from each other by $1.5 \mu \mathrm{m}$ in the order of increasing loading rates). ${ }^{33}$

indicating that at any loading rate, the instability is setting in after the same time, $t_{\mathrm{c}}$, which in the case of $\mathrm{Al}-3 \mathrm{Mg}$ alloy was found to be $7.3 \mathrm{~s}$. Taking into account the equivalent strain rate ${ }^{66,67}$

$$
\dot{\epsilon}_{\mathrm{eq}}=\frac{1}{h} \cdot \frac{\partial h}{\partial t},
$$

which is continuously decreasing during indentation, and the approximation in Eq. (1), we get that during indentation

$$
\dot{\epsilon}_{\mathrm{eq}}(t) \approx \frac{1}{t}
$$

According to Eqs. (11) and (13), it can be concluded that plastic instability occurs if the equivalent strain rate, $\dot{\epsilon}_{\text {eq }}$ becomes smaller than the upper critical strain rate

$$
\dot{\epsilon}_{\mathrm{c}}=\frac{1}{t_{\mathrm{c}}} \approx \frac{1}{7.3} \cdot \mathrm{s}^{-1}
$$

the magnitude of which is in good agreement with that obtained by uniaxial tensile on $\mathrm{Al}-4.5 \% \mathrm{Mg}$ alloy. ${ }^{68}$

\section{Effect of solute concentration on the occurrence of the instability steps}

From the nature of the interaction between mobile dislocations and diffusing solute atoms, it can be expected that the solute concentration must exceed a certain minimal value, $C_{\mathrm{o}}$, for negative strain rate sensitivity to appear. However, neither theoretical nor experimental data are available about the minimum (critical) $\mathrm{Mg}$ concentration (which is necessary to get plastic instabilities), not even for Al-Mg alloys, on which the PLC effect is most frequently studied.

Figure 8 shows some typical indentation depth-load curves taken on $\mathrm{Al}-\mathrm{Mg}$ alloys with different $\mathrm{Mg}$ concentrations. The curve measured on the most dilute alloy is smoothly changing, indicating no indentation instability for $\mathrm{Mg}$ concentration of $0.45 \mathrm{wt} \%$. The indentation instability occurs only in the case of the more concentrated solid solutions, for which instability steps appear in the $F-h$ curves. It should be emphasized that in the case of the investigated solid-solution $\mathrm{Al}-\mathrm{Mg}$ alloys, the indentation curves are well reproducible; the storage at RT even if it is as long as 2 years after quenching has no effect on the occurrence and development of the steps on the indentation curves.

To characterize the plastic instability (depth-load) steps, the slowly changing part of the $F-h$ curves-which could be very accurately fitted with Eq. (3)

$$
F_{\text {fit }}=K \cdot h^{\alpha},
$$

or

$$
h_{\mathrm{fit}}=B \cdot F^{n},
$$

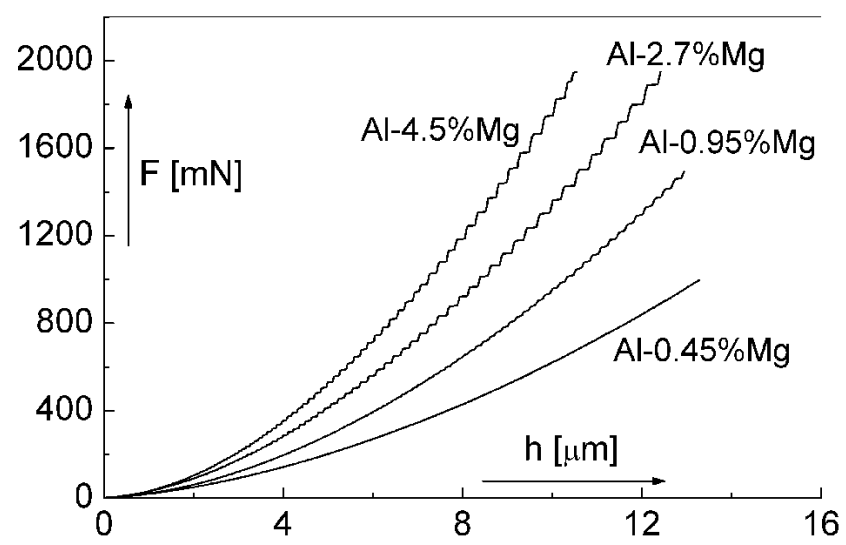

FIG. 8. Indentation depth-load curves of different concentration AlMg alloys. ${ }^{16}$ 
power-law functions, where $\alpha$ is about 1.75 to $1.8, n=$ $1 / \alpha$, and $K$ and $B$ are composition-dependent constantshas been subtracted from the original $F_{\text {measured }}$ curves. The amount of

$$
\Delta F=F_{\text {measured }}-F_{\text {fit }}
$$

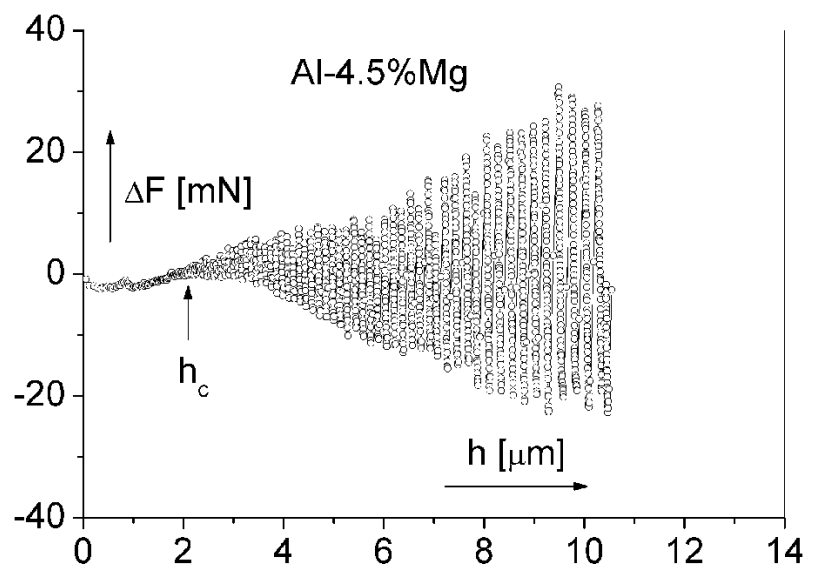

(a)

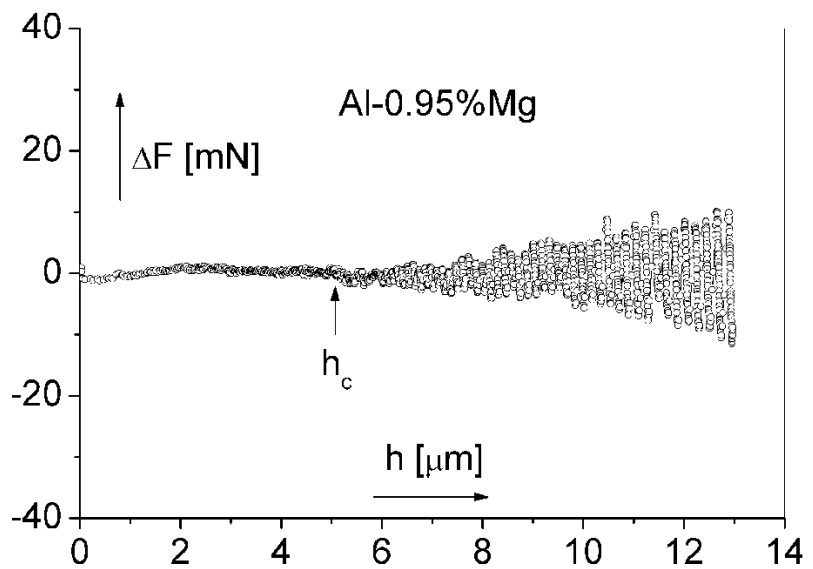

(b)

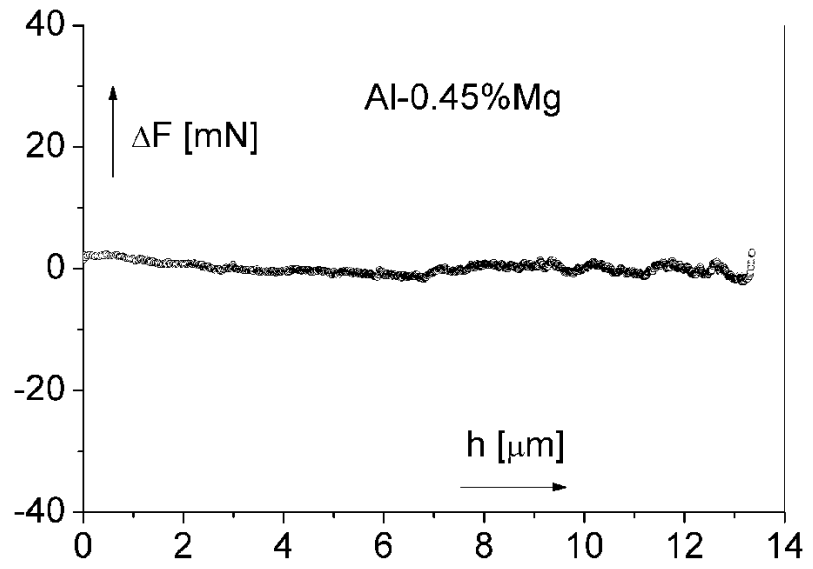

(c)

FIG. 9. The occurrence and the development of the load deviations, $\Delta F$, in $\mathrm{Al}-\mathrm{Mg}$ alloys with $\mathrm{Mg}$ content of (a) $4.5 \mathrm{wt} \%$, (b) $0.95 \mathrm{wt} \%$, and (c) $0.45 \mathrm{wt} \% .^{16}$ at a given depth then indicates the deviation of the load from that necessary for keeping the global (dynamically stable) behavior. The $\Delta F$ versus $h$ curves (Fig. 9)despite some inevitable experimental error-clearly show that the occurrence and development of the plastic instabilities depend strongly on the solute content. At higher Mg contents [Fig. 8 as well as Fig. 9(a) and 9(b)], very definite steps and $\Delta F$ load oscillations can be observed which become less pronounced when the solute content is decreasing. It can also be seen that the value of the critical depth, $h_{\mathrm{c}}$, increases with decreasing solute content. In the case of $0.45 \mathrm{wt} \% \mathrm{Mg}$ [Fig. 9(c)], the value of $\Delta F$ is practically zero in the whole indentation process; no steps can be observed. Therefore, it should be concluded that in this sample, plastic instability does not occur. This result is obviously in agreement with the physical basis of the dynamic strain ageing process for which a certain solute concentration is necessary; that is, the plastic instabilities occur only if the solute concentration is larger than a critical $C_{\mathrm{o}}$ concentration.

To determine the critical $\mathrm{Mg}$ content, the values of the critical depth, $h_{\mathrm{c}}$, have been plotted as a function of the solute content, $C$. To the $h_{\mathrm{c}}-C$ data shown in Fig. 10, the

$$
h_{c}=K\left(C-C_{\mathrm{o}}\right)^{\mathrm{n}}\left(C>C_{\mathrm{o}}\right) \text {, }
$$

power-law function can be fitted with the parameters of

$$
\begin{gathered}
K=2.91 \pm 0.15 \mu m, \\
C_{\mathrm{o}}=0.86 \pm 0.04(w t \%),
\end{gathered}
$$

and

$$
n=-0.23 \pm 0.04
$$

from which the function (16) can be given approximately as

$$
h_{c}=2.9(C-0.86 w t \%)^{-1 / 4} \text {. }
$$

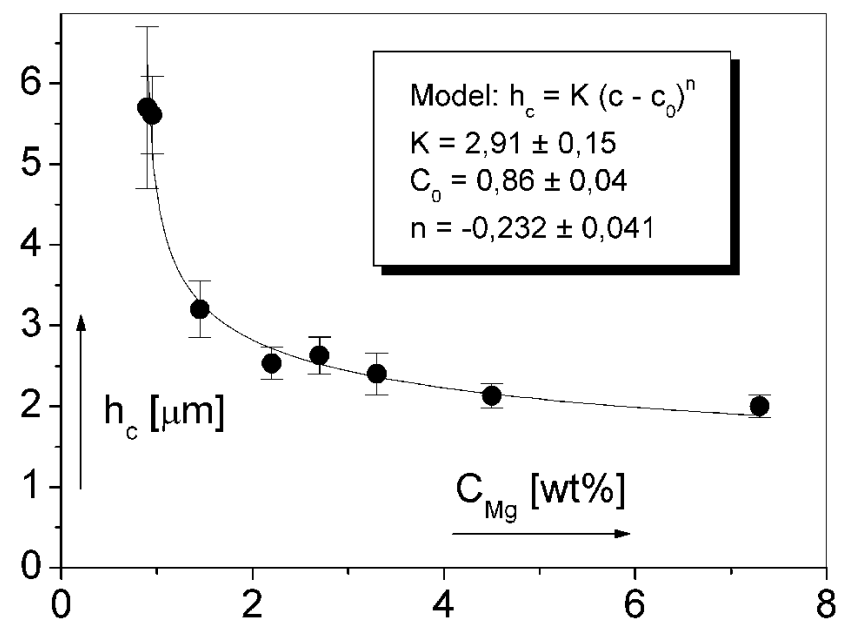

FIG. 10. Concentration dependence of the critical indentation depth, $h_{\mathrm{c}}$, in $\mathrm{Al}-\mathrm{Mg}$ alloys. ${ }^{16}$ 
The decrease of $h_{\mathrm{c}}$ with increasing solute content is clearly a consequence of the higher number of solute atoms taking part in the dynamic strain ageing effect. According to Eq. (17), if the $\mathrm{Mg}$ contents decrease to the value of $0.86 \mathrm{wt} \%, h_{\mathrm{c}}$ tends to infinity. This means that at $\mathrm{Mg}$ content, $C \leqslant 0.86 \mathrm{wt} \%$, plastic instabilities cannot occur in Al-Mg alloys. The validity of Eq. (17) seems to be confirmed by the fact that in the case of Mg content, $C=0.45 \mathrm{wt} \%$ plastic instabilities were not observed in the indentation process.

As an additional support of the existence of the critical $\mathrm{Mg}$ content mentioned above, it should be noted that a theoretical critical value of $\mathrm{Mg}$ concentration has also been estimated. ${ }^{16}$ According to a model proposed by $\mathrm{Ku}-$ bin and Estrin, ${ }^{49}$ where the critical strain is correlated with the strain dependence of the densities of mobile and forest dislocations, the strain rate sensitivity becomes negative $(\mathrm{SRS} \leqslant 0)$, if the

$$
X \exp (-X)=\frac{3 S_{\mathrm{o}}}{2 f_{\mathrm{o}}},
$$

equation has solutions, where the quantity $X$ is the ratio of the waiting time, $t_{\mathrm{w}}$ of the dislocation at obstacles, and the diffusional relaxation time $t_{0}$ of the solute cloud ( $X=$ $\left.t_{\mathrm{w}} / t_{0}\right)$. In the formula (18), $S_{\mathrm{o}}$ is the SRS in the absence of dynamic strain ageing, and $f_{\mathrm{o}}$ is the maximum increment in stress which can be produced by the ageing mechanism. Because the maximal value of $X \exp (-X)$ function is $1 / e$, Eq. (18) has a solution if

$$
\frac{3 S_{\mathrm{o}}}{2 f_{\mathrm{o}}} \leq \frac{1}{e}
$$

or

$$
f_{\mathrm{o}} \geq \frac{3 S_{\mathrm{o}} \cdot e}{2}
$$

from which a value of $C_{0}=0.62 \mathrm{wt} \%$ can be obtained for the theoretical critical concentration. ${ }^{16}$ Although the value of this theoretical critical content depends on several parameters as, for example, on strain rate through $f_{\mathrm{o}}$, it is in reasonable agreement with the $0.86 \mathrm{wt} \%$ obtained experimentally by depth-sensing indentation test.

It has also been shown ${ }^{36}$ that in the case of $\mathrm{Al}-\mathrm{Cu}$ alloys, on the basis of the experimentally measured $h_{\mathrm{c}}-C$ connection, a value of $C_{0}=0.2 \mathrm{wt} \%$ was found for the critical concentration of $\mathrm{Cu}$. Some further details about indentation instability in $\mathrm{Al}-\mathrm{Cu}$ alloys are discussed in the next section.

\section{The effect of decomposition on the development of the indentation instability in supersaturated solid solutions}

It is well known that in age-hardenable alloys like $\mathrm{Al}-\mathrm{Cu}$ or $\mathrm{Al}-\mathrm{Zn}-\mathrm{Mg}$ alloys, following the quenching, from the supersaturated solid solution Guinier-Preston
(GP) zones are formed at RT. ${ }^{69}$ This so-called natural ageing process changes strongly the microstructural and mechanical properties of the alloys. By applying conventional mechanical testing methods, previous works ${ }^{46,61,70}$ have shown that the formation of GP zones influences strongly the occurrence of serrated yielding; it increases the onset strain considerably. In the following, the effect of GP zone formation on the development of the indentation instability occurring in $\mathrm{Al}-\mathrm{Cu}$ and $\mathrm{Al}-\mathrm{Zn}-\mathrm{Mg}$ alloys ${ }^{35-37,39}$ will be summarized.

\section{a. Al-Cu alloys: The effect of solute content}

Figure 11 shows indentation depth-load curves of alloys with different $\mathrm{Cu}$ concentrations naturally aged at $\mathrm{RT}$ for different times, $t_{\mathrm{a}}$. It was mentioned in Sec. II. C. 2 that instability steps occur only in binary $\mathrm{Al}-\mathrm{Cu}$ alloys containing at least $0.2 \mathrm{wt} \% \mathrm{Cu}{ }^{36}$ Figure 11 demonstrates that the development of the steps depends strongly both on the $\mathrm{Cu}$ content and on the ageing time, $t_{\mathrm{a}}$. While in the case of $\mathrm{Cu}$ concentration $\mathrm{C} \leqslant 1 \mathrm{wt} \%$, steps are well reproducible and appear even after several months of $t_{\mathrm{a}}$, on the $\mathrm{Al}-2 \mathrm{wt} \% \mathrm{Cu}$ alloy, the instability steps disappeared after one day and on the $\mathrm{Al}-3 \mathrm{wt} \% \mathrm{Cu}$ alloy after a few hours [Figs. 11(b) and 11(c)].

The behavior of the higher $\mathrm{Cu}$ concentration $(C=2$ and $3 \mathrm{wt} \%$ ) alloys is the consequence of the formation of GP zones in these alloys. Early investigation ${ }^{36}$ of the Vickers microhardness, $H V_{2 \mathrm{~N}}$, of the Al-Cu alloys during RT ageing revealed that while the hardness of the $\mathrm{Al}-1 \% \mathrm{Cu}$ alloy remains practically constant with increasing $t_{\mathrm{a}}$, the hardness of the higher $\mathrm{Cu}$ content alloys is strongly increasing. The increasing hardness indicates the strengthening due to the formation of GP zones. By comparing the results of the Vickers microhardness measurements with the development of the instability steps on the indentation curves, it can be concluded that the occurrence of the plastic instabilities is connected to the solid-solution state of the alloys. In dilute alloys $(C \leqslant$ $1 \%$ ), GP zones do not form (or form very slowly); consequently, these alloys remain solid solutions for a long time after quenching, therefore plastic instabilities (indentation steps) were always observed. In the case of higher solute contents, where GP zones form rapidly, the disappearance of the plastic instabilities is connected to the effect of GP zones, that is, the interaction of dislocations with GP zones becomes dominant compared to that with solute atoms and so the formation of GP zones suppresses the plastic instabilities, consequently the plastic instabilities disappear at a certain state of decomposition of the alloy.

\section{b. Effect of $\mathrm{Cu}$ addition on GP zone formation and indentation instability in $\mathrm{Al}-\mathrm{Zn}-\mathrm{Mg}$ alloys}

Figure 12 shows some typical indentation depth-load $(h-F)$ curves obtained on a ternary $\mathrm{Al}-5.7 \mathrm{Zn}-1.9 \mathrm{Mg}$ and 

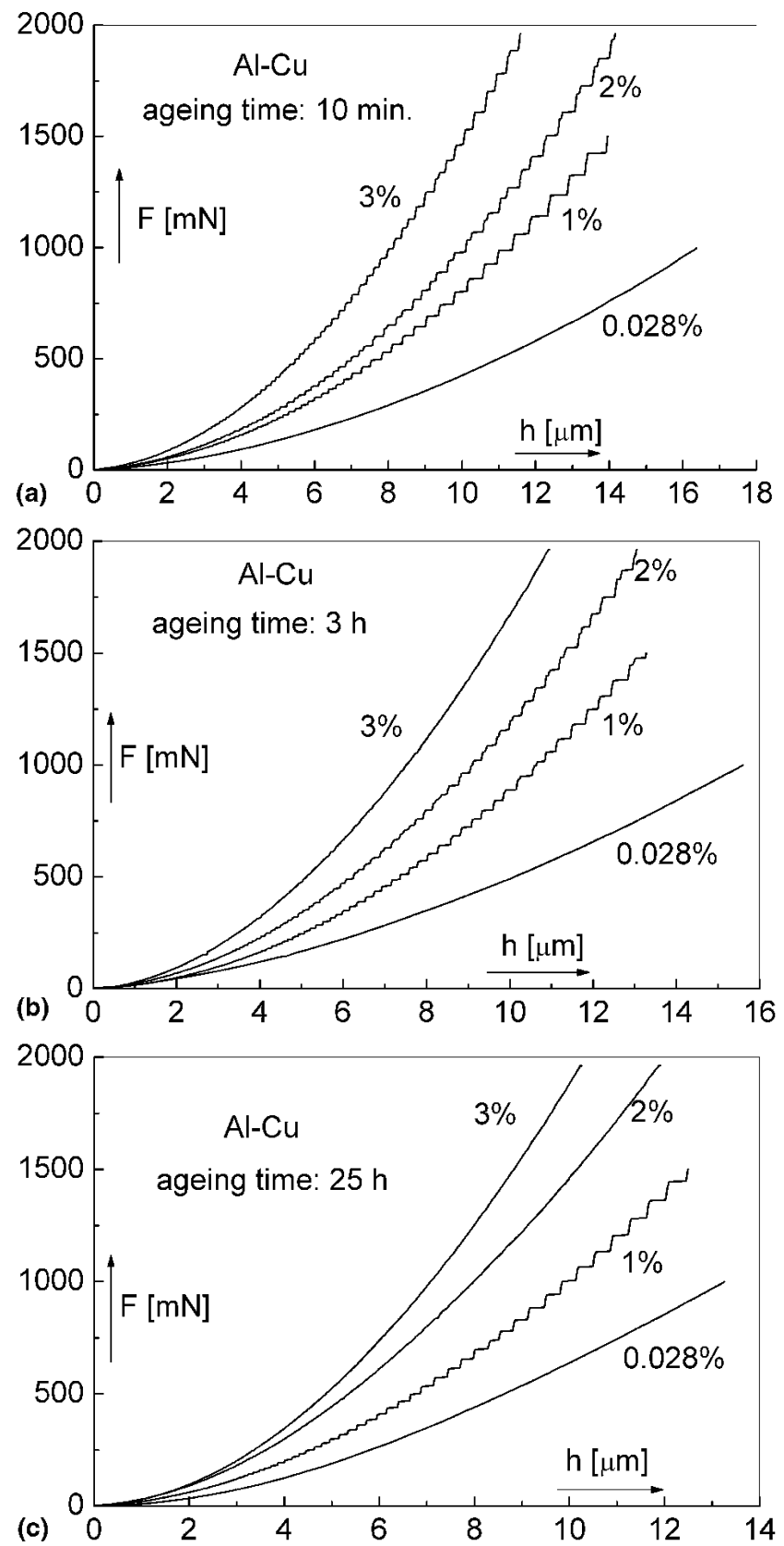

FIG. 11. The indentation curves taken on different $\mathrm{Cu}$ concentration $\mathrm{Al}-\mathrm{Cu}$ alloys after ageing for $t_{\mathrm{a}}$ : (a) $10 \mathrm{~min}$, (b) $3 \mathrm{~h}$, (c) $25 \mathrm{~h}^{36}$

on a quaternary $\mathrm{Al}-5.7 \mathrm{Zn}-1.9 \mathrm{Mg}-0.35 \mathrm{Cu}$ alloy in the early stages of natural ageing. It can be seen that in the initial period of natural ageing instability steps appear in the $h-F$ curves for both alloys. With longer ageing times the steps occur less frequently, the process becomes less regular and, finally, after a certain ageing time they disappear completely, and smooth $h-F$ curves are obtained. ${ }^{35,37,39}$ Therefore, it should be concluded that for ageing times longer than a characteristic lifetime $t_{i}$, plastic instability does not occur during indentation. Figure 13 shows the influence of natural (RT) ageing in
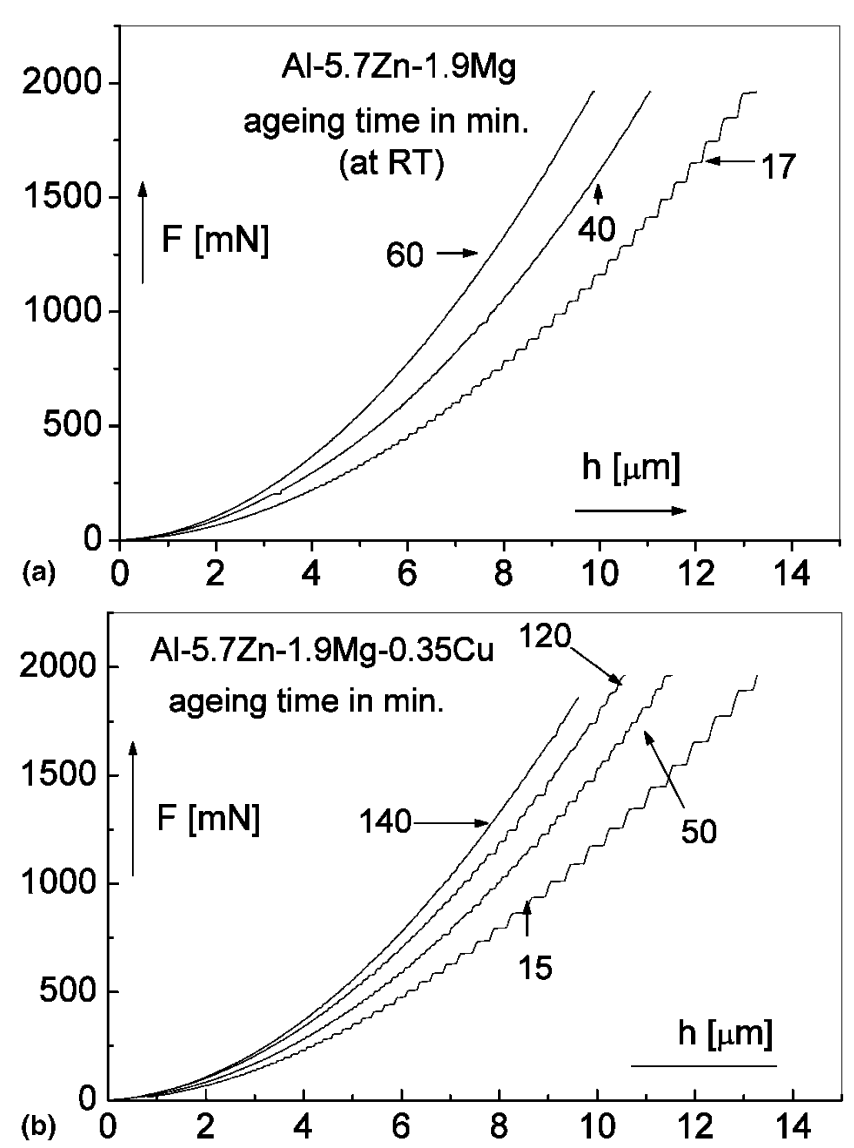

FIG. 12. Indentation curves of (a) $\mathrm{Al}-5.7 \mathrm{Zn}-1.9 \mathrm{Mg}$ and (b) $\mathrm{Al}-$ $5.7 \mathrm{Zn}-1.9 \mathrm{Mg}-0.35 \mathrm{Cu}$ alloys after different ageing times at RT. ${ }^{39}$

the early stage on the Vickers microhardness of both alloys. The fast initial increase in the microhardness revealed that GP zones start to form at RT immediately (within 10 minutes) after quenching. The changes of $H V$ show also the effect of adding a relatively small amount of $\mathrm{Cu}$ to $\mathrm{Al}-\mathrm{Zn}-\mathrm{Mg}$ alloys. It can be seen that after the practically same initial value of $H V$, which can be regarded roughly as the hardness of the solid-solution state, the initial rate of hardening is decreased by the addition of $\mathrm{Cu}$ so that within a certain stage of natural ageing, the microhardness of the $\mathrm{Cu}$-containing alloy-despite the higher alloying content - is lower than that of the ternary $\mathrm{Al}-\mathrm{Zn}-\mathrm{Mg}$ alloy. In the later stage of natural ageing, however, the $\mathrm{Cu}$ containing alloy makes up on the ternary $\mathrm{Al}-\mathrm{Zn}-\mathrm{Mg}$, and after about $24 \mathrm{~h}$ of ageing there is no difference between the hardness of the two alloys.

The plastic instability steps can be characterized also by the statistics of the indentation velocity, $V=\partial(\Delta h) / \partial t$, where $\Delta h=h_{\text {fit }}-h_{\text {measured }}$ is the deviation of the measured indentation depth, $h_{\text {measured }}$, from the stable behavior described by $h_{\text {fit }}$ in Eq. (14). ${ }^{39}$ The velocity, $V$, then describes the oscillation rate of the indenter relative to the stable behavior, and obviously its value is permanently about zero if plastic instabilities do not occur be- 


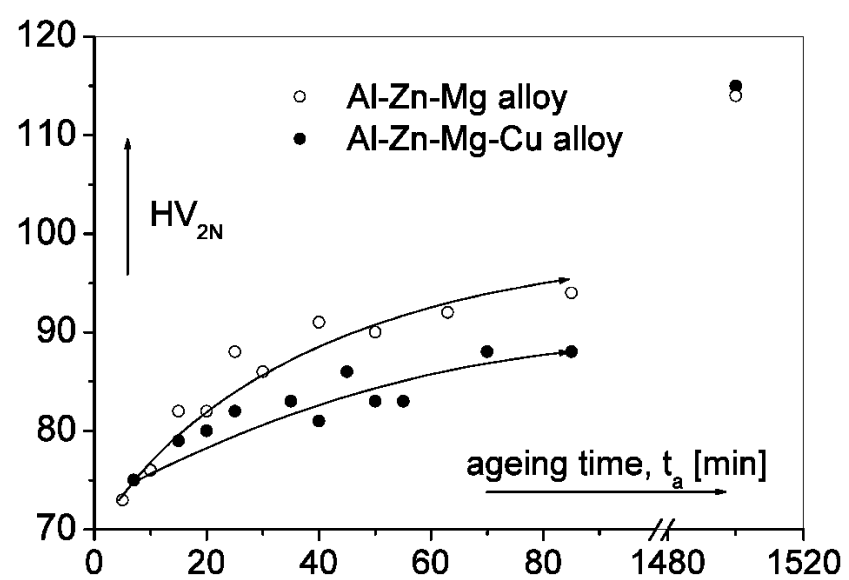

FIG. 13. The influence of natural ageing on the Vickers microhardness of the $\mathrm{Al}-5.7 \mathrm{Zn}-1.9 \mathrm{Mg}$ and $\mathrm{Al}-5.7 \mathrm{Zn}-1.9 \mathrm{Mg}-0.35 \mathrm{Cu}$ alloys. ${ }^{39}$

cause in this case the depth-deviation, $\Delta h$, is about zero during indentation. Figure 14 shows the distributions of the velocity, $V$, obtained for the $\mathrm{Al}-\mathrm{Zn}-\mathrm{Mg}-\mathrm{Cu}$ alloy after different ageing times. For short ageing times, the most frequent value of $V$ is relatively far from zero, indicating plastic instabilities in the initial stage of natural ageing, and for increasing ageing time this value tends to zero, indicating the disappearance of the instability process. Figure 15 shows the value of the most frequent velocity, $V_{\mathrm{mf}}$, as a function of the ageing time. From the tendency of this function, the value of lifetime, $t_{\mathrm{i}}$, for the $\mathrm{Cu}$-containing alloy can be estimated to be about 135 min, which is at least three times higher than that estimated for the ternary $\mathrm{Al}-\mathrm{Zn}-\mathrm{Mg}$ alloy, in which the instability steps disappear within $40 \mathrm{~min}$ of natural ageing.

The occurrence of plastic instabilities is caused by the interaction of diffusing solute atoms with moving dislocations; the occurrence of the instability steps and the corresponding microhardness oscillations is in connection with the solid-solution phase of the alloys. The disappearance of plastic instabilities, however, may be the consequence of (i) the decrease of the solute concentration in the solid solution matrix and/or (ii) the varying internal structure of the sample. In the age-hardenable $\mathrm{Al}-\mathrm{Zn}-\mathrm{Mg}-(\mathrm{Cu})$ alloys, the instability steps became irregular before their complete disappearance, and they sometimes disappear and reappear during indentation. This suggests that the disappearance of plastic instabilities is caused rather by the varying microstructure. With the formation of GP zones after a short period of ageing, the alloy is no more a single-phase solid solution. The occurrence of the instability steps in the early stage of the ageing process, however, indicates that initially the GP zones are not strong enough to suppress the DSA effect. At the point when the effect of GP zones on moving dislocations becomes dominant compared to that of the solute atoms, the instability steps disappear from the in-

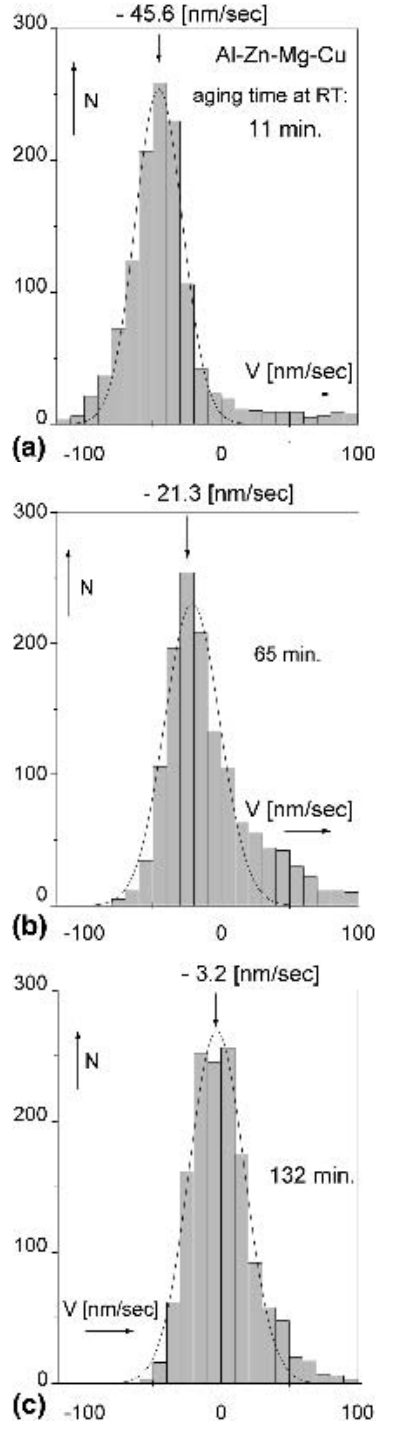

FIG. 14. The distribution of the velocity of the indenter around the global behavior after ageing time of (a) $11 \mathrm{~min}$, (b) $65 \mathrm{~min}$, and (c) 132 $\min { }^{39}$

dentation curves. Therefore, the lifetime, $t_{\mathrm{i}}$, of the plastic instabilities characterizes a definite state in the zone formation process. Both the facts that the values of $t_{\mathrm{i}} \mathrm{ob}-$ tained for the $\mathrm{Cu}$-containing alloy is at least three times longer than that obtained for the ternary $\mathrm{Al}-\mathrm{Zn}-\mathrm{Mg}$ alloy and that the initial rate of hardening is decreased by $\mathrm{Cu}$ indicate that the addition of $\mathrm{Cu}$ retards the formation of GP zones in the initial part of the decomposition process.

\section{c. Comparison with results of constant loading rate tensile tests}

Figure 16 shows some experimental results obtained by indentation and tensile tests on the initial period of natural ageing in a fine-grained $\mathrm{Al}-4.8 \mathrm{Zn}-1.2 \mathrm{Mg}-0.14 \mathrm{Zr}$ alloy. ${ }^{37}$ Since the size of the indent at maximum load is 


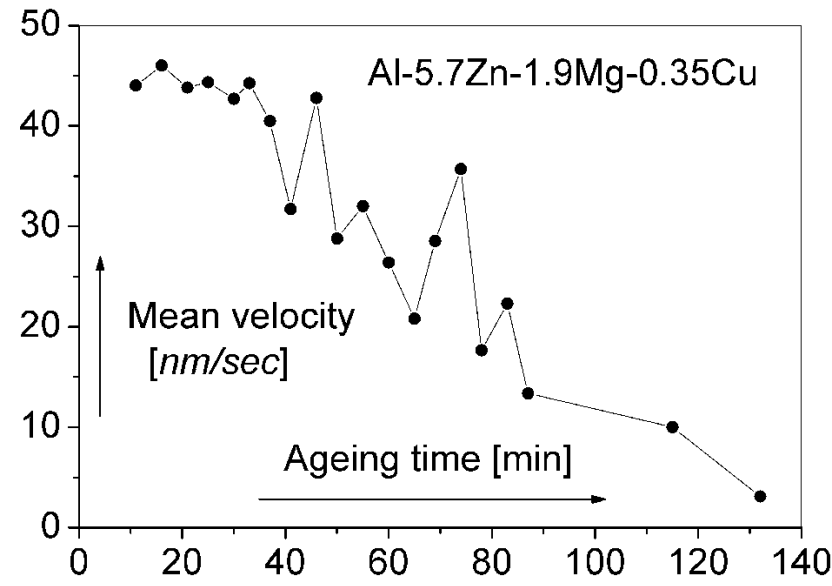

FIG. 15. The value of the most frequent indenter-velocity, $V_{\mathrm{mf}}$, as a function of the ageing time, $t_{\mathrm{a}} \cdot{ }^{39}$

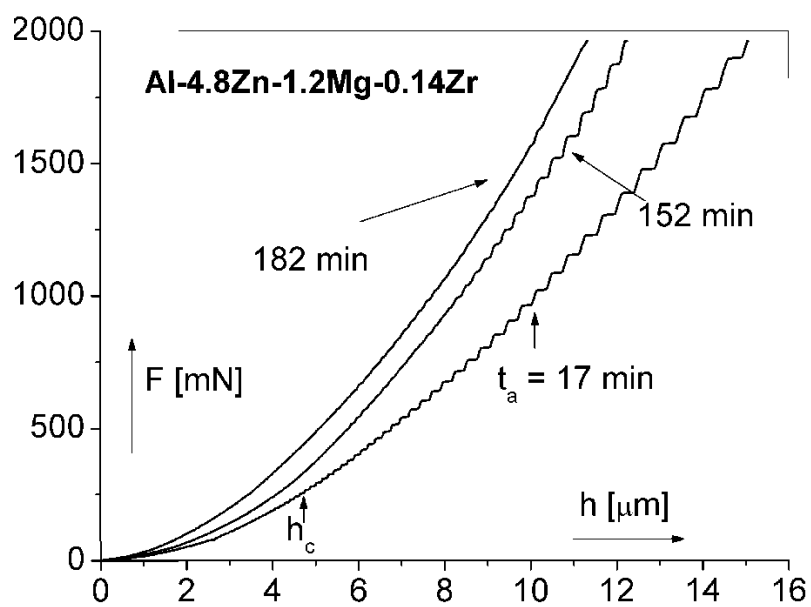

(a)

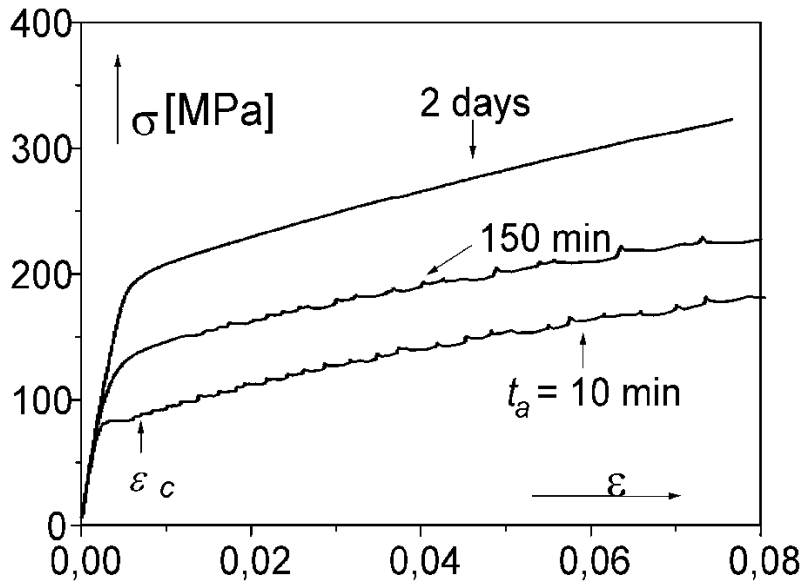

(b)

FIG. 16. (a) Indentation $(F-h)$ and (b) tensile $(\sigma-\epsilon)$ curves of an $\mathrm{Al}-4.8 \mathrm{Zn}-1.2 \mathrm{Mg}-0.14 \mathrm{Zr}$ alloy after different ageing times at $\mathrm{RT}{ }^{37}$

about $60-80 \mu \mathrm{m}$, because of the small average grain size $(d<10 \mu \mathrm{m})$ of the sample, the indentation measurements reflect also the macroscopic (polycrystalline) behavior in the case of this alloy. The indentation curves as a func- tion of ageing time [Fig. 16(a)] show similar development than in the case of the $\mathrm{Al}-\mathrm{Zn}-\mathrm{Mg}-(\mathrm{Cu})$ alloy mentioned above. In this alloy, however, the instability steps are retained for more than $150 \mathrm{~min}$, which can be explained by taking into account the lower solute concentration and the consequently lower thermodynamic driving force for GP zone formation. It can also be seen in Fig. 16(a) that the critical depth, $h_{c}$, increases with increasing ageing time, $t_{\mathrm{a}}$.

The stress-strain $(\sigma-\epsilon)$ curves of the constant loading rate $(10 \mathrm{~N} / \mathrm{s})$ tensile measurements [Fig. 16(b)] reflect also both the plastic instabilities and the effect of GP zone formation. In the early stages of ageing, step-like strain-jumps can be observed on the $\sigma-\epsilon$ curves from a critical (onset) strain, $\epsilon_{\mathrm{c}}$. The increase of the proof stress and of the onset strain with increasing ageing time, $t_{\mathrm{a}}$, is again due to the strengthening effect of GP zones. A similar effect was observed in an $\mathrm{Al}-\mathrm{Zn}-\mathrm{Mg}-\mathrm{Cu}$ alloy. ${ }^{46}$ By comparing the results of indentation and tensile tests, it can be concluded that the increase of critical indentation depth, $h_{\mathrm{c}}$, is corresponding to the increase of the onset strain, $\epsilon_{\mathrm{c}}$, in conventional tensile test.

\section{d. Orientation dependence of Portevin-Le Châtelier plastic instabilities}

As it was mentioned in the previous section, PLC indentation instabilities were observed in the early stages of GP zone formation in supersaturated $\mathrm{Al}-\mathrm{Zn}-\mathrm{Mg}-\mathrm{Cu}$ alloys. Investigating the phenomenon in different orientations of grains relative to the direction of indentation, it was shown that ${ }^{38}$ the occurrence of PLC effect depends also on the orientation of the grain. If the direction of the indentation is close to the $\langle 100\rangle$ crystal axis and the diagonal of the Vickers indenter coincides with the $\langle 110\rangle$ crystal direction, the PLC effect is the most pronounced. Under these conditions, the instabilities can be observed even after $5 \mathrm{~h}$ of natural ageing whereas in other orientations, the PLC effect disappears within two hours of ageing.

Investigations of PLC instabilities ${ }^{71}$ in uniaxial deformation of singe crystals also pointed out that the changes from a single slip to a multiple slip condition correlate well with the decrease of the critical strain. For depthsensing indentation tests, considering only the compressive stress component in the sample/indenter contact planes, in the vicinity of the indenter single-slip-like and multiple-slip-like conditions are attained, depending on the orientation of the indenter relative to the sample. The special orientation, in which instabilities can be observed for a longer period, corresponds to a multiple slip condition at the contact surface of the indenter. This causes the occurrence of plastic instabilities at a lower critical strain in single slip orientations, leading to the orientation dependence of the dynamical hardness even in highly isotropic materials like aluminium alloys. 


\section{e. Effect of grain size on plastic deformation processes during indentation}

Recently, by applying the so-called equal channel angular pressing (ECAP) technique,$^{72-74}$ the grain size of annealed $\mathrm{Al}-3 \% \mathrm{Mg}$ alloy was reduced from approximately $400 \mu \mathrm{m}$ to about $300 \mathrm{~nm} .{ }^{41}$ The occurrence and development of instability indentation steps in the case of this ultrafine-grained material depends strongly on the indentation size. Indentation instabilities were observed only at small indentation sizes with indentation depths of $<1000 \mathrm{~nm}$. In the microindentation regime with indentation depths of $>1000 \mathrm{~nm}$, in contrast to the behavior of the annealed, coarse-grained sample, the ultrafinegrained sample did not show any traces of the plastic instabilities.

The appearance of the PLC plastic instabilities in the ultrafine-grained material deformed by submicrometer indent sizes indicates that in these conditions, intragranular dislocation motion plays a decisive role. At large indentation sizes, however, dislocation motion within the grains makes only a limited contribution to the plastic deformation and instead grain boundary processes become rate controlling. The transition from dislocation motion at small indentations to a predominately grain boundary mechanism at large indentations was estimated to take place when the deformation volume during indentation extends to the volume of approximately 1000 grains in the fine-grained sample. ${ }^{41}$

The effect of individual grain boundaries on the PLC effect in depth-sensing Vickers indentation was also investigated. ${ }^{42}$ As the result of the influence of grain boundaries on the indentation instabilities, two kinds of phenomena were found. The first, so-called small-step event, when irregular and smaller steps appeared besides the regularly developing steps, is attributed to PLC steppings with nearly constant phase shift in neighboring grains. The other, so-called large-step event, when unexpectedly large steps occurred on the indentation curves, is the direct consequence of the formation of dislocation pile-ups at the grain boundary and the overshooting of the plastic deformation after the pile-up dislocations are released by the boundary.

\section{f. Depth-sensing indentation with other shape indenters}

In a recent paper, ${ }^{40}$ it was shown that depth-sensing indentation tests using conical and cylindrical indenters are also suitable to study PLC plastic instabilities. Comparison of the results obtained by different testing methods-uniaxial tension, conical, and Vickers indentation-was achieved through representative strain and stress quantities. According to these representative quantities, the representative stress drop, $\Delta \sigma_{\mathrm{r}}$, characterizing indentation instabilities can be given in the form ${ }^{40}$

$$
\Delta \sigma_{\mathrm{r}}=\frac{1}{\beta} \frac{\Delta F_{\mathrm{p}}}{A},
$$

where $\Delta F_{\mathrm{p}}$ is the load increment in a given instability step (Fig. 6) occurring at the projected indentation area, $A$, and $\beta \approx 3.0$. The quantity, $\Delta \sigma_{\mathrm{r}}$, shows good coincidence for Vickers and conical indentations and for the large strain region of the tension tests. The same value of $\Delta \sigma$ obtained for different types (pyramidal, conical) of sharp indenters is a consequence of the self-similarity of the plastically deformed volume during indentation with these indenters.

The coincidence of the quantity, $\Delta \sigma_{\mathrm{r}}$, in indentation using sharp indenters with the $\Delta \sigma$ for large strains in tensile experiments indicates that the initialization of the PLC instabilities during indentation occurs close to the indenter head/sample interface where the strain is the highest. $^{40}$

\section{INTERPRETATION OF THE DEVELOPMENT OF INSTABILITY STEPS DURING DEPTH-SENSING INDENTATION}

As it has been mentioned in Sec. II. A, in the case of uniaxial (e.g., tensile and compression) deformation there are several works ${ }^{48-51}$ focused on the interpretation of Portevin-Le Châtelier type plastic instabilities. So far, although the DSI process was also adequately modeled by finite element simulation applied for different kinds of materials, ${ }^{75,76}$ no theoretical works were published in detail on the description of plastic instabilities during depth-sensing indentation. In the following, a simple interpretation is given on the development of instability steps observed in DSI measurements.

In Sec. II. C. 1, it was shown that in the case of solid-solution $\mathrm{Al}-\mathrm{Mg}$ alloys, the load increment $\Delta F_{\mathrm{p}}$ is approximately proportional to the load, $F$ (i.e., in a given measurement the ratio $\Delta F_{\mathrm{p}} / F$ is constant during indentation. Figure 17 shows the measured $\Delta F_{\mathrm{p}} / F$ values as a function of solute concentration for $\mathrm{Al}-\mathrm{Mg}$ alloys. ${ }^{37}$ With increasing $\mathrm{Mg}$ concentration, $\Delta F_{\mathrm{p}} / F$ increases monotonically.

The strain field under the tip in the indentation tests is strongly inhomogeneous. It can be supposed, however, that each elementary volume of the deformation zone under the indenter tip undergoes the same deformation procedure as the whole sample in tensile tests. This means that in the plastically deformed zone of the specimen, each elementary volume reaches the same value of critical strain, $\epsilon_{\mathrm{c}}$, once during the indentation process. Consequently, the deformation zone can be divided into two parts. One of them is in the negative strain rate sensitivity (SRS) regime and shows PLC effect; the other one has normal positive SRS. According to the work of Tabor, ${ }^{77}$ the deformation zone under the tip can be regarded as geometrically self-similar, from which the ratio 


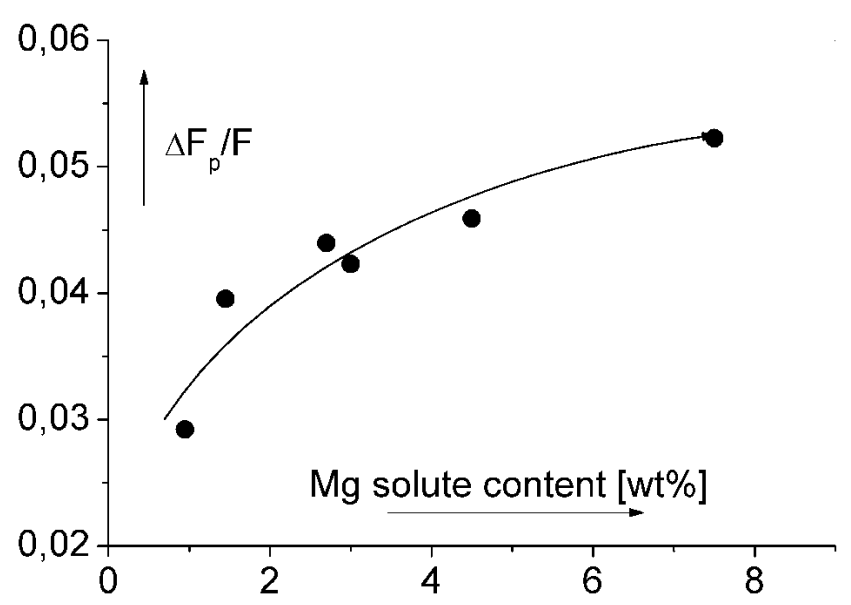

FIG. 17. $\Delta F \mathrm{p} / F$ values for different solute concentrations in $\mathrm{Al}-\mathrm{Mg}$ alloys. $^{37}$

of the negative SRS volume, $V_{\mathrm{PLC}}$, and the total plastic deformation zone, $V_{\text {TOTAL }}$

$$
f=\frac{V_{\mathrm{PLC}}}{V_{\text {TOTAL }}},
$$

remains constant in the whole indentation process. The ratio $f$, of course, is a function of the critical strain, $\boldsymbol{\epsilon}_{\mathrm{c}}$, for a given indenter type. Although there is no information about the exact shape of the $f\left(\epsilon_{\mathrm{c}}\right)$ function, it is evident that $f\left(\epsilon_{\mathrm{c}} \rightarrow 0\right)=1$ and $f\left(\epsilon_{\mathrm{c}} \rightarrow \infty\right)=0$.

Using these assumptions, the average stress drop in the whole plastically deformed zone under the indenter is $\Delta \sigma \cdot f\left(\epsilon_{\mathrm{c}}\right)$, where $\Delta \sigma$ is the stress drop calculated theoretically from the $\mathrm{N}$-shaped $\sigma(\dot{\epsilon})$ function shown in Fig. 2, which is supposed to remain approximately constant in the whole negative SRS domain. Although it is complicated to derive the connection between the load increments $\Delta F$ and the average stress drops, it is reasonable to assume the following form

$$
\Delta F_{\mathrm{p}}=C_{1} \cdot \Delta \sigma \cdot f\left(\epsilon_{\mathrm{c}}\right) \cdot h^{2},
$$

where $C_{1}$ is a dimensionless geometrical constant and $h$ is the indenter depth at load $F$. Taking into account the definition of the microhardness in Eq. (2) ( $H V=$ const . $F / h^{2}$ ) and the approximate proportionality between the microhardness of the material and the yield stress, $\sigma,{ }^{77}$ the relationship between the load, $F$, and the yield stress, $\sigma$, can be expressed as

$$
\frac{F}{h^{2}}=C_{2} \cdot \sigma,
$$

where $C_{2}$ is also a constant. From Eqs. (22) and (23) we get:

$$
\frac{\Delta F_{\mathrm{p}}}{F}=\frac{C_{1}}{C_{2}}\left(\frac{\Delta \sigma}{\sigma}\right) f\left(\epsilon_{\mathrm{c}}\right)
$$

In the case of a given solute concentration, beside the constant value of $f\left(\epsilon_{\mathrm{c}}\right), \Delta \sigma$ and $\sigma$ are also constant, at least at high strains. ${ }^{40}$ The model described above, therefore, predicts the proportionality of $\Delta F_{\mathrm{p}}$ to $F$ giving back the experimental results. It should be emphasized that although no information on the exact form of the strain field under the indenter was used, the validity of Eq. (24) may confirm the assumption of the constancy of $f\left(\epsilon_{\mathrm{c}}\right)$ ratio during indentation. Furthermore, the changes in $\Delta F_{\mathrm{p}} / F$ shown in Fig. 17 suggest that the volume fraction of the negative SRS region is changing with solute concentration.

\section{PLASTIC INSTABILITIES-SERRATED FLOW-IN BULK METALLIC GLASSES DURING INDENTATION}

Serrated plastic flow has recently been observed during nanoindentation on BMGs. The phenomenonsimilarly as in crystalline alloys-manifested itself as discrete steps in the load-depth indentation curve. ${ }^{65,75,76,78-84}$ In crystalline alloys, the physical basis for the appearance of plastic instabilities is the negative strain rate sensitivity originating mainly from the interaction between mobile dislocations and diffusing solute atoms. In the case of BMGs, being noncrystalline materials, the mechanism of the appearance of instability steps must be different. Results of indentation and microscopic investigations on BMG materials have shown that each discrete pop-in event in the loading curve corresponded to the operation of an individual shear band. ${ }^{76,79,80}$ Despite the different mechanisms, both in crystalline alloys and in BMG materials the loading rate has a significant effect on the character of the indentation curve. Figure 18 shows, for instance, typical load-depth $(F-h)$ curves obtained for four different loading rates in the range of $0.6-20 \mathrm{mN} / \mathrm{s}$ on $\mathrm{Pd}-40 \mathrm{Ni}-20 \mathrm{P}$ (at.\%) bulk metallic glass. ${ }^{81}$ At low loading rates (generally under 10 $\mathrm{mN} / \mathrm{s}$ ), the steps in the loading curve can clearly be observed. In the indentation curve, the displacements, $\Delta \mathrm{D}_{\mathrm{p}}$, occurring in the bursts also increase linearly with the increase of the penetration depth, $h{ }^{65}$ As the loading rate increases, the stair-step-like $P-h$ curves become smooth parabolic curves. ${ }^{65,81}$ The transition from completely discrete flow to completely continuous yielding occurs smoothly over a broad, four-decade range of loading rate. $^{65}$ The effect of loading rate on the serrated indentation curve was studied by Schuh et al. ${ }^{65}$ for two Pdbased and two Zr-based BMGs with different compositions across loading rates of several orders of magnitude. It is found that the character of serrated flow depends strongly on the composition of BMGs. The Pd-based alloys exhibit sharper displacement bursts than for $\mathrm{Zr}$ based materials at the same loading rate, and the $\mathrm{Zr}$ based alloys show a broader range of loading rate over 


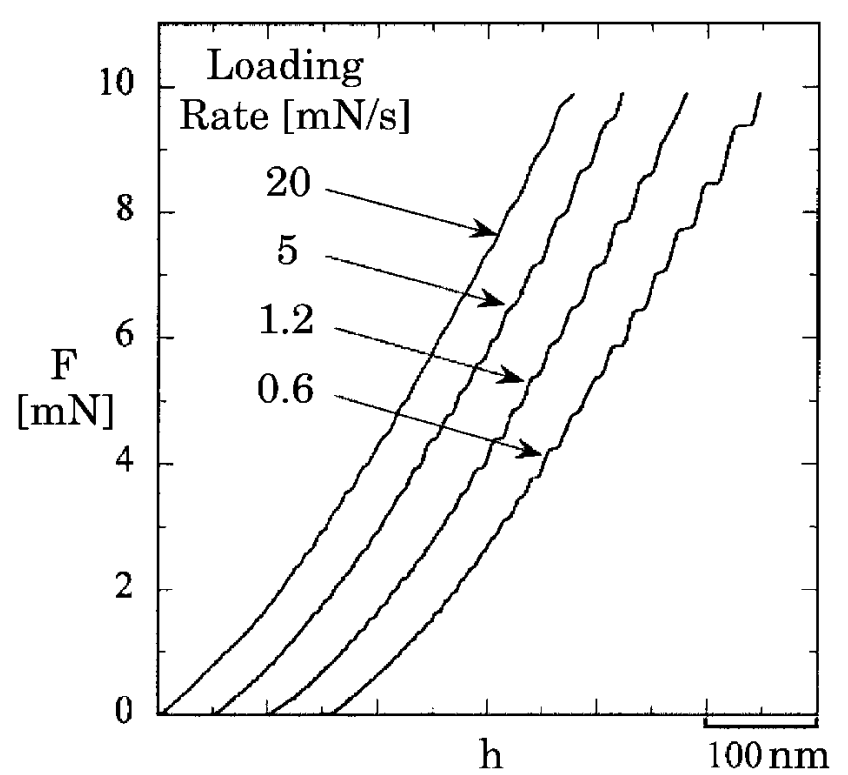

FIG. 18. Indentation depth-load curves of a Pd-40Ni-20P BMG measured at different loading rates. ${ }^{81}$

which the transition occurs. ${ }^{65}$ The compositional dependence of serrated flow suggests the importance of the local atomic arrangements and the composition near the shear bands.

Schuh et al. ${ }^{65}$ have corrected the experimental loading curve by discounting the plastic deformation performed in the bursts for $\mathrm{Pd}-30 \mathrm{Cu}-10 \mathrm{Ni}-20 \mathrm{P}$ alloy at different loading rates. This method was first proposed by Gouldstone et al. ${ }^{85}$ At very low loading rate $(0.08 \mathrm{mN} / \mathrm{s})$, the corrected curve is smooth and its shape is similar to the unloading curve where the deformation is purely elastic. The maximum elastic displacement measured in unloading is also very close to the maximum depth of the corrected loading curve, indicating that at sufficiently slow indentations all the plastic strain occurs in the discrete bursts. ${ }^{65}$ For higher loading rates, the corrected loading curve deviates significantly from the elastic unloading curve.

The results of the indentation experiments mentioned above can be explained by the shear band propagation during plastic deformation in BMGs. ${ }^{65}$ If the strain rate is slow, the applied strain can be accommodated by a single shear band resulting in a displacement step in the indentation curve. For high strain rates, many shear bands are required to accommodate the imposed deformation, therefore discrete steps in the indentation curve cannot be observed. The strain rate decreases both with the decrease of the loading rate and the increase of the indentation depth in a single loading curve. Consequently, the steps in the loading curve become more significant with the decrease of the loading rate or the increase of the penetration depth. Extensive atomic force microscope observations ${ }^{76,83,84}$ revealed clearly both the shear band
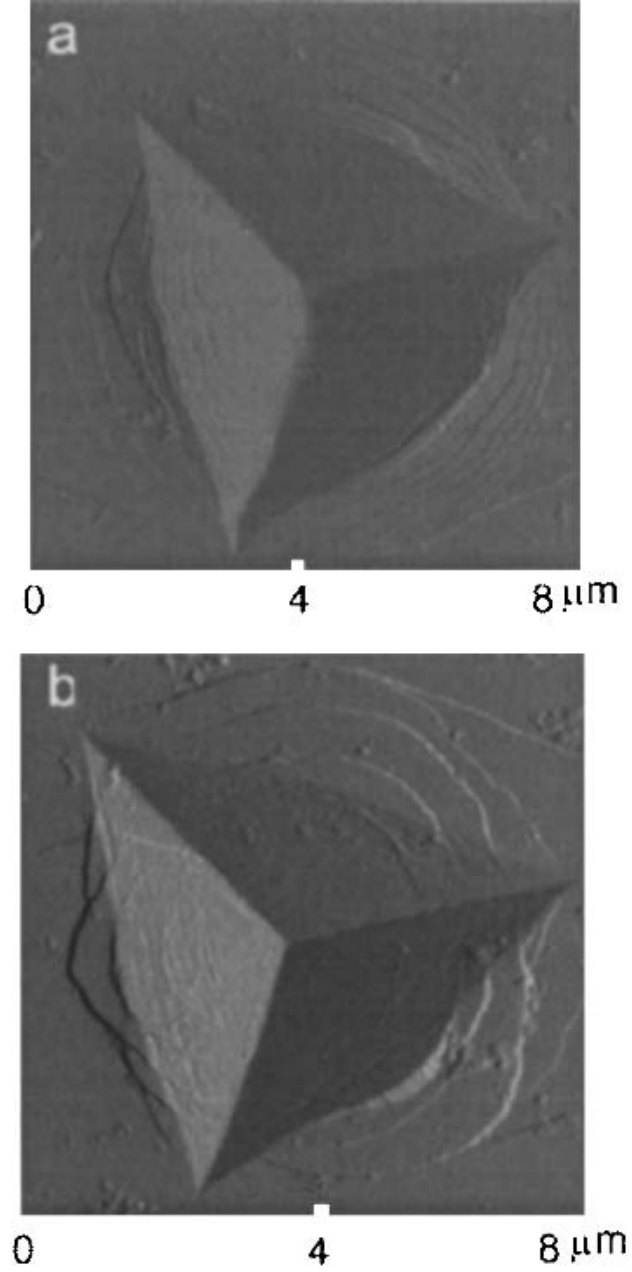

FIG. 19. AFM illumination images of indents produced at penetration rates of (a) $100 \mathrm{~nm} / \mathrm{s}$ and (b) $1 \mathrm{~nm} / \mathrm{s}$ on amorphous $\mathrm{Al}_{90} \mathrm{Fe}_{5} \mathrm{Gd}_{5}$ ribbon. ${ }^{84}$

propagation and its loading-rate dependence. Typical morphologies of indents produced by Jiang et al. ${ }^{84}$ on amorphous $\mathrm{Al}_{90} \mathrm{Fe}_{5} \mathrm{Gd}_{5}$ ribbon at relatively high and low penetration rates, $100 \mathrm{~nm} / \mathrm{s}$ and $1 \mathrm{~nm} / \mathrm{s}$ (corresponding to average loading rates of about $5 \mathrm{mN} / \mathrm{s}$ and $0.05 \mathrm{mN} / \mathrm{s}$, respectively) are shown in illumination-mode atomic forec microscopy images in Fig. 19. Surface steps due to shear bands can be observed around and in the indents. Furthermore, the number of shear bands is smaller and the step size is larger outside the indent formed at the lower penetration rate. The large step size of the shear band propagation is the reason of the visible step-like indentation. The authors of the work ${ }^{84}$ also showed that the finer shear bands formed at high rates are not reflected in depth-load curves.

\section{SUMMARY AND CONCLUSIONS}

In this paper, the phenomenon of plastic instabilities occurring in depth-sensing indentation measurements 
was reviewed. Investigations were focused on the characterization of Portevin-Le Châtelier type instabilities observed in different metal alloys and the main results can be summarized as follows.

(1) It was shown that the load-depth indentation curves obtained for different alloys are not always smoothly changing functions, but may contain characteristic steps. This means that, dynamically, the local behavior of the material deviates from the global one, indicating the occurrence of plastic instabilities during indentation. The smooth background component of the indentation curves could accurately be fitted with the $F_{\text {fit }}=K \cdot h^{\mathrm{m}}$ or $h_{\text {fit }}=B \cdot F^{\mathrm{n}}$ power-law functions. The plastic instability (depth-load) steps can be characterized with the amount of load deviation $\Delta F=F_{\text {measured }}-F_{\text {fit }}$ and/or the velocity, $V=\partial\left(h_{\text {measured }}-h_{\text {fit }}\right) / \partial t$, of the indenter around the global behavior

(2) In the case of stable solid-solution alloys such as $\mathrm{Al}-\mathrm{Mg}$, relatively regular depth-load steps are observed in the indentation curves. Analyzing the development of the instability steps, it has been shown that the step height, $\Delta D_{\mathrm{p}}$, and load period, $\Delta F_{\mathrm{p}}$, are proportional to the total indentation depth and total load, respectively. It was also shown that the occurrence and development of steps depends strongly on the loading rate and on the solute content. It was demonstrated that the plastic instabilities occur only if the solute concentration is larger than a critical $C_{\mathrm{o}}$ concentration; for Al-Mg alloys at RT, $C_{\mathrm{o}}$ was found to be $0.86 \mathrm{wt} \% \mathrm{Mg}$.

(3) In the case of age-hardenable alloys such as $\mathrm{Al}-$ $\mathrm{Cu}$ or $\mathrm{Al}-\mathrm{Zn}-\mathrm{Mg}-(\mathrm{Cu})$ alloys, the characterization of the steps is influenced also by decomposition (GuinierPreston zone formation). On the basis of the analysis of indentation instability, it was concluded that the addition of $\mathrm{Cu}$ retards the initial part of the decomposition process at $\mathrm{RT}$ in $\mathrm{Al}-\mathrm{Zn}-\mathrm{Mg}$ alloys.

(4) A connection between the load increments $\left(\Delta F_{\mathrm{p}}\right)$ in the indentation instability steps and the theoretical stress drop $(\Delta \sigma)$ has been established, from which the development of instability steps could be interpreted.

(5) The phenomenon of plastic instabilities as serrated flow recently observed in BMGs is in connection with shear band propagation.

\section{ACKNOWLEDGMENTS}

This article is dedicated to Professor István Kovács on the occasion of his 70th birthday.

This work was supported by the Hungarian National Scientific Research Fund (OTKA) under Contract Nos. T-038048, F-047057, and T-043247. J.G. is grateful for the financial support of Magyary Zoltán postdoctoral program of Foundation for Hungarian Higher Education and Research (AMFK).

\section{REFERENCES}

1. B.R. Lawn and V.R. Howes, J. Mater. Sci. 16, 2745 (1981).

2. M. Sakai, Acta Metall. Mater. 41, 1751 (1993).

3. R.F. Cook and G.M. Pharr, J. Hard. Mater. 5, 179 (1994)

4. A.E. Giannakopoulos, P.L. Larsson, and R. Vestergaard, Int. J. Solids Struct. 31, 2679 (1994).

5. P.L. Larsson, A.E. Giannakopoulos, E. Söderlund, E. Rowcliffe, and R. Vestergaard, Int. J. Solids Struct. 33, 221 (1996).

6. Y.T. Cheng and C.M. Cheng, Appl. Phys. Lett. 73, 614 (1998).

7. T.A. Venkatesh, K.J. Van Vliet, A.E. Giannakopoulos, and S. Suresh, Scr. Mater. 42, 833 (2000).

8. J.B. Pethica, R. Hutchings, and W.C. Oliver, Philos. Mag. A 48, 593 (1983)

9. M. Atkinson, J. Mater. Res. 10, 2908 (1995).

10. J. Mencik and M.V. Swain, J. Mater. Res. 10, 1491 (1995).

11. W.D. Nix and H. Gao, J. Mech. Phys. Solids 46, 411 (1988).

12. L.G. Hector and S.R. Schmid, Wear 215, 247 (1998).

13. S.R. Schmid and L.G. Hector, Wear 215, 257 (1998).

14. K. Zeng and C-h. Chiu, Acta Mater. 49, 3539 (2001).

15. A. Krell and S. Schadlich, Mater. Sci. Eng. A 307, 172 (2001).

16. N.Q. Chinh, F. Csikor, Zs. Kovács, and J. Lendvai, J. Mater. Res. 15, 1037 (2000).

17. X. Ma, F. Yoshida, and K. Shinbata, Mater. Sci. Eng. A 344, 296 (2003).

18. F. Fröhlich, P. Grau, and W. Grellmann, Phys. Status Solidi (a) 42, 79 (1977).

19. J. Gubicza, A. Juhász, P. Tasnádi, P. Arató, and G. Vörös, J. Mater. Sci. 31, 3109 (1996).

20. J. Gubicza, A. Juhász, and J. Lendvai, J. Mater. Res. 11, 2964 (1996).

21. J. Gubicza, A. Juhász, P. Arató, P. Szommer, P. Tasnádi, and G. Vörös, J. Mater. Sci. Lett. 15, 2141 (1996).

22. G.M. Pharr, W.C. Oliver, and F.R. Brotzen, J. Mater. Res. 7, 613 (1992).

23. W.C. Oliver and G.M. Pharr, J. Mater. Res. 7, 1564 (1992).

24. F.R. Brotzen, Int. Mater. Rev. 39, 24 (1994).

25. W.J. Pool, M.F. Ashby, and N.A. Fleck, Scr. Mater. 34, 559 (1996).

26. J.L. Bucaille, S. Stauss, E. Felder, and J. Michler, Acta Mater. 51, 1663 (2003).

27. Z. Li, Y.T. Cheng, H.T. Yang, and S. Chandrasekar, Surf. Coat. Technol. 154, 124 (2002).

28. B. Wolf, M. Swain, M. Kempf, and P. Paufler, J. Mater. Sci. 35, 723 (2000).

29. G.M. Pharr, W.C. Oliver, and D.R. Clarke, Scr. Metall. 23, 1949 (1989).

30. D.S. Stone and K.B. Yoder, J. Mater. Res. 9, 2524 (1994).

31. S.V. Hainsworth, M.R. McGurk, and T.F. Page, Surf. Coat. Technol. 102, 97 (1998).

32. E.G. Berasategui and T.F. Page, Surf. Coat. Technol. 163-164, 491 (2003).

33. G. Bérces, N.Q. Chinh, A. Juhász, and J. Lendvai, Acta Mater. 46, 2029 (1998).

34. G. Bérces, N.Q. Chinh, A. Juhász, and J. Lendvai, J. Mater. Res. 13, 1411 (1998).

35. N.Q. Chinh, G. Németh, A. Fekete, and J. Lendvai, Alum. Alloys 2, 621 (1998).

36. N.Q. Chinh, F. Csikor, Gy. Bérces, and J. Lendvai, Alum. Alloys 2, 979 (1998).

37. N.Q. Chinh, F. Csikor, and J. Lendvai, Mater. Sci. Forum 331-337, 1007 (2000).

38. Zs. Kovács, N.Q. Chinh, and J. Lendvai, J. Mater. Res. 16, 1171 (2001).

39. N.Q. Chinh, Gy. Horváth, Zs. Kovács, and J. Lendvai, Mater. Sci. Eng. A 324, 219 (2002). 
40. Zs. Kovács, N.Q. Chinh, J. Lendvai, and G. Vörös, Mater. Sci. Eng. A 325, 255 (2002).

41. Zs. Kovács, N.Q. Chinh, J. Lendvai, Z. Horita, and T.G. Langdon, Mater. Sci. Forum 396-402, 1073 (2002).

42. Zs. Kovács, D. Fátay, K. Nyilas, and J. Lendvai, J. Eng. Mater. Technol. 124, 23 (2002).

43. H. Neuhäuser and C. Schwink, in Materials Science and Technology, edited by H. Mughrabi ( $\mathrm{VCH}$, Weinheim, Germany, 1993), Vol. 6, p. 191.

44. Y.J.M. Bréchet, Key Eng. Mater., 103, 21 (1995).

45. P.G. McCormick, Scr. Metall. 15, 441 (1982).

46. D. Thevenet, M. Mliha-Touati, and A. Zeghloul, Mater. Sci. Eng. A 266, 175 (1999).

47. P. Penning, Acta Metall. 20, 1169 (1972).

48. P.G. McCormick, Acta Metall. 20, 351 (1972).

49. L.P. Kubin and Y. Estrin, Acta Metall. 38, 697 (1990).

50. Y. Bréchet and Y. Estrin, Acta Metall. 43, 955 (1995).

51. S. Kok, M.S. Bharathi, A.J. Beaudoin, C. Fressengeas, G. Ananthakrishna, L.P. Kubin, and M. Lebyodkin, Acta Mater. 51, 3651 (2003).

52. R. Král, P. Lukáč, and M. Janeček, Mater. Sci. Forum 217-222, 1025 (1996).

53. E. Pink and A. Grinberg, Acta Metall. 30, 2153 (1982).

54. A.H. Cottrell, Philos. Mag. 44, 829 (1953).

55. A. Van den Beukel, Phys. Status Solidi (a) 30, 197 (1975).

56. J.M. Robinson and M.P. Shaw, Int. Mater. Rev. 39, 113 (1994).

57. J.M. Robinson, Int. Mater. Rev. 39, 217 (1994).

58. L.P. Kubin, K. Chihab, and Y. Estrin, Acta Metall. 36, 2707 (1988).

59. P.G. McCormick, S. Venkadesan, and C.P. Ling, Scr. Metall. 29, 1159 (1993).

60. P.G. McCormick and C.P. Ling, Acta Metall. Mater. 43, 1969 (1995).

61. P. Lukáč, J. Balík, and F. Chmelík, Mater. Sci. Eng. A 234-236, 45 (1997).

62. H.M. Zbib and E.C. Aifantis, Scripta Metall. 22, 1331 (1988).

63. P. Hähner, Mater. Sci. Eng. A 164, 23 (1993).

64. P.G. McCormick, Acta Metall. 30, 2079 (1982).

65. C.A. Schuh and T.G. Nieh, Acta Mater. 51, 87 (2003).

66. M.S. Bobji and S.K. Biswas, in Recent Advances in Metallurgical
Processes, edited by D.H. Sastry, E.S. Dwarakadasa, G.N.K. Iyengar, and S. Subramanian, (New Age Int. Publishers, New Delhi, 1977), p. 1223.

67. W.H. Poisl, W.C. Oliver, and B.D. Fabes, J. Mater. Res. 10, 2024 (1995).

68. R. Král and P. Lukáč, Mater. Sci. Eng. A 234-236, 786 (1997).

69. R.W. Cahn, Physical Metallurgy (American Elsevier Publishing Co. Inc., New York, 1970).

70. E. Pink, Acta Metall. 37, 1773 (1989).

71. A. Kalk, A. Nortmann, and Ch. Schwink, Philos. Mag. A 72, 1239 (1995).

72. Y. Iwahashi, J. Wang, Z. Horita, M. Nemoto, and T.G. Langdon, Scr. Mater. 35, 143 (1996).

73. M. Furukawa, Y. Iwahashi, Z. Horita, M. Nemoto, and T.G. Langdon, Mater. Sci. Eng. A 257, 328 (1998).

74. M. Furukawa, Z. Horita, M. Nemoto, and T.G. Langdon, J. Mater. Sci. 36, 2835 (2001).

75. M. Dao, N. Chollacoop, K.J. Van Vliet, T.A. Venkatesh, and S. Suresh, Acta Mater. 49, 3899 (2001).

76. R. Vaidyanathan, M. Dao, G. Ravichandran, and S. Suresh, Acta Mater. 49, 3781 (2001).

77. D. Tabor, Microindentation Techniques in Materials Science and Engineering, ASTM STP 889, edited by P.J. Blau and B.R. Lawn (American Society for Testing and Materials, Philadelphia, PA, 1986), p. 129.

78. W.J. Wright, R. Saha, and W.D. Nix, Mater. Trans. JIM 42, 642 (2001).

79. J.J. Kim, Y. Choi, S. Suresh, and A.S. Argon, Science 295, 654 (2002).

80. Y.I. Golovin, V.I. Ivolgin, V.A. Khonik, K. Kitagawa, and A.I. Tyurin, Scr. Mater. 45, 947 (2001).

81. C.A. Schuh, T.G. Nieh, and Y. Kawamura, J. Mater. Res. 17, 1651 (2002).

82. T.G. Nieh, C.A. Schuh, J. Wadsworth, and Y. Li, Intermetallics 10, 1177 (2002).

83. T. Benameur, K. Hajlaoui, A.R. Yavari, A. Inoue, and B. Rezgui, Mater. Trans. JIM 43, 2617 (2002).

84. W.H. Jiang and M. Atzmon, J. Mater. Res. 18, 75 (2003).

85. A. Gouldstone, H.J. Koh, K.Y. Zeng, A.E. Giannakopoulos, and S. Suresh, Acta Mater. 48, 2277 (2000). 